\title{
Energy Management of Plug-in Hybrid Electric Vehicles with Unknown Trip Length
}

\author{
Cong Hou ${ }^{\mathrm{a}}$, Liangfei Xu ${ }^{\mathrm{a}}$, Hewu Wang ${ }^{\mathrm{a}}$, Minggao Ouyang ${ }^{\mathrm{a}, *}$, Huei Peng ${ }^{\mathrm{b}}$ \\ ${ }^{a}$ State Key Laboratory of Automotive Safety and Energy, Tsinghua University, Beijing, China \\ ${ }^{b}$ Department of Mechanical Engineering, University of Michigan, Ann Arbor, MI, USA
}

\begin{abstract}
This paper proposes a novel control strategy for plug-in hybrid electric vehicles (PHEV). The minimization of the utility factor weighted fuel consumption $\left(\mathrm{FC}_{\mathrm{UFW}}\right)$, which represents the average fuel consumption in numerous trips, is firstly proposed as the objective of the energy management. In previous studies, the trip length is usually assumed to be known. Then, if it is shorter than the all-electric range (AER), a Charge Depleting-Charge Sustaining (CDCS) strategy leads to the minimum fuel consumption; otherwise, a blended strategy that spends down battery energy almost uniformly brings the minimum fuel consumption. Nevertheless, the trip length is not always known before trip in real life. To deal with the cases of unknown trip length, this paper proposes a Range ADaptive Optimal Control (RADOC) strategy to minimize the $\mathrm{FC}_{\mathrm{UFW}}$, which utilizes the statistical information of the trip length. The RADOC strategy was verified by dynamic programming and was found to be somewhere in between the blended and CDCS strategies. Depending on the nature of the trips, the RADOC strategy was found to improve $\mathrm{FC}_{\mathrm{UFW}}$ between $0.10 \%$ and $4.07 \%$ compared with the CDCS strategy. The RADOC strategy is very close to the CDCS strategy when the PHEV is used in regular daily driving. On the contrary, the RADOC solution exhibits a "uniform battery discharging" behavior similar to the blended strategy for urban utility vehicles or taxis. The behavior of the RADOC strategy is also studied for different battery sizes and driving cycles.
\end{abstract}

Keywords: PHEV, energy management, optimal control, dynamic programming

\section{Introduction}

Plug-in hybrid electric vehicles (PHEV) are natural extension of hybrid electric vehicles [1] , which have captured 3.5\% of the US market and about 20\% of the Japanese market in 2012. Several PHEV models are now available in the US, including Toyota Prius plug-in [2], Chevy Volt [3] , and C-MAX/Fusion Energi from Ford [4] . PHEV replaces some of the petroleum fuel with grid electricity and helps energy diversification [5] [6] . Bigger battery enables more petroleum displacement. In addition, through better energy management strategy (EMS), the fuel consumption can be further reduced without any additional cost. EMS reduces fuel consumption by optimizing the power split between engine and electric machine(s). There is a large body of literature on EMS for HEVs [7] [8] [9] , but relatively few for PHEVs.

The rule-based Charge Depleting-Charge Sustaining (CDCS) strategy is a simple EMS for

*Corresponding author: Minggao Ouyang, Tel: (+86)-10-62785706, E-mail: ouymg@tsinghua.edu.cn 
PHEV [5] . Because the vehicle uses all electricity in the charge depleting (CD) stage, it is also known as All Electric-Charge Sustaining (AECS) strategy. With the AECS strategy, the vehicle only utilizes the electric energy above a certain battery State of Charge (SOC) threshold. After that, the powertrain shifts to charge sustaining. During the charge sustaining phase, the vehicle operates like a conventional HEV, which optimizes fuel consumption using both power sources. The AECS strategy is not necessarily close to optimal [10] [11] . The advantage of this strategy is that the control rule is simple. Besides, it also maximizes electricity usage which results in minimal liquid fuel consumption for average drivers when the battery has been sized for adequate trip length [12] . A drawback of this strategy is the requirement for large electric machine(s) for all-electric propulsion and thus higher cost.

When the trip length is known and is longer than the all-electric range of the battery, the AECS strategy is less than optimal [13]. This fact was confirmed by using the dynamic programming (DP) technique [14] [15] and by Pontryagin's Minimum Principle [16] [17] . In the true optimal solution, the fuel and electricity are blended to propel the vehicle from the very beginning [18] [19] . The electric energy is used nearly at a constant pace throughout the trip [7] . The AECS strategy and the blended strategy solved by DP are illustrated in Figure 1[20] .

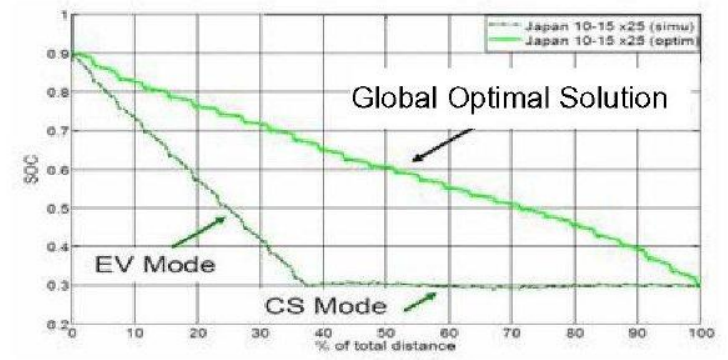

(a) SOC Profile

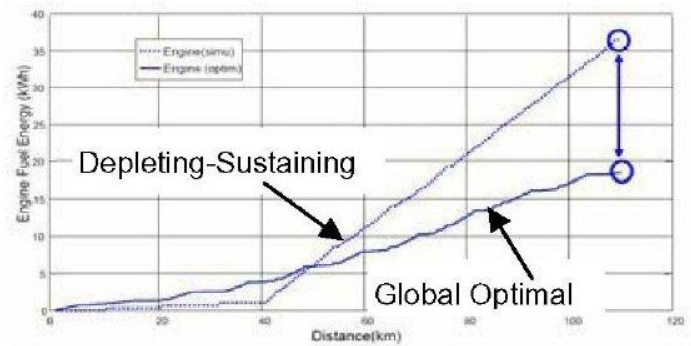

(b) Fuel Consumption

Figure 1. PHEV power management using global optimization method

While the blended strategy reveals the nature of the optimal solution, it assumes that the trip length is known. The trip length can be manifested when GPS is used and driver daily routine is learned, or when driver input is received. For many other cases, trip length is not known (e.g., for taxi drivers). In these cases, neither AECS strategy, nor blended strategy can guarantee the minimum fuel consumption. If the trip length is longer than the all-electric range (AER), the blended strategy is better than the AECS strategy; otherwise, the AECS strategy is better, because it utilizes the grid electricity in prior to the fuel. Even for the cases with the trip length longer than AER, the blended strategy still cannot promise the optimal fuel consumption, unless the charge depleting range is carefully designed to match the trip length. From the perspective of average fuel consumption in numerous trips, a former study declares that some of the blended strategies are 
even less optimal than the simple AECS strategy [12] .

To deal with cases with unknown trip lengths, this paper now proposes a Range Adaptive Optimal Control (RADOC) strategy. The utility factor weighted fuel consumption $\left(\mathrm{FC}_{\mathrm{UFw}}\right)$, which represents the average fuel consumption in numerous trips, is the objective of the proposed RADOC strategy. The initial definition of $\mathrm{FC}_{\mathrm{UFW}}$ comes from SAE J2841 standard [21] , utilizing the travel statistics collected in National Household Travel Survey (NHTS) [22] With the US utility factor, the $\mathrm{FC}_{\mathrm{UFW}}$ means the average fuel consumption if the PHEV is driven by a typical American driver. Furthermore, when the utility factor is derived based on some one's personal travel statistics, the $\mathrm{FC}_{\mathrm{UFW}}$ will be a good estimation of the average fuel consumption for the PHEV driven by him. When the proposed control strategy is combined with the blended strategy, the combined strategy can deal with cases of both known and unknown trip lengths. When the trip length is known, an appropriate blended strategy will be adopted to give the PHEV the minimum fuel consumption for next trip; otherwise, the RADOC strategy will be utilized to minimize the average fuel consumption based on the historical trip statistics. After all, the key to the ideal combined solution is the RADOC strategy, which aims at minimizing the average fuel consumption. The idea of minimizing the $\mathrm{FC}_{\mathrm{UFW}}$ is proposed for the first time, noticing the significant impact of the trip length on the average fuel consumption of PHEVs.

The rest of the paper is organized as follows: in Section 2, the definition of the utility factor weighted fuel consumption is reviewed; in Section 3, the models used in this study are introduced, and the optimization problem, to minimize the utility factor weighted fuel consumption is solved by dynamic programming; in Section 4, scenarios with different range distributions, different PHEV configurations and different cycles are analyzed; and finally in Section 5, conclusions are provided.

\section{Utility Factor Weighted Fuel Consumption $\mathbf{F C}_{\text {UFW }}$}

The concept of utility factor was described in SAE J2841 [21] and SAE J1711 [23] . The utility factor (UF) is derived from the daily travel range data obtained in NHTS. Given the all-electric-range of a PHEV, let's say, $x$ miles, the corresponding $\operatorname{UF}(x)$ is the utility, or service, provided by the battery energy for all the trips in the NHTS. The denominator of $\operatorname{UF}(x)$ is the sum of all trips (which is independent of $x$ ), and the numerator of $\operatorname{UF}(x)$ consists of two parts: the first part is the total range of all trips shorter than or equal to $x$ miles; and the second part is the first $x$-miles of all trips longer than $x$ miles [21] . As an example, the utility factor of the US trips for a PHEV with 40-mile all electric range was 63\%, and in concept that means such PHEV, when widely deployed, could displace $63 \%$ of gasoline/diesel consumption by electricity. Similar survey conducted in Beijing found the $63 \%$ utility factor corresponds to a 25-mile range [24] .

Based on the concept of utility factor, the utility factor weighted fuel consumption, $\mathrm{FC}_{\mathrm{UFW}}$, is defined [21] . First, the UF is calculated for each cycle. And the utility factor for each cycle is called cycle UF. The $\mathrm{FC}_{\mathrm{UFW}}$ is then defined as the sum of the products of the cycle UFs and their corresponding fuel consumption, shown as Equation 1.

$$
F C_{U F W}=\sum_{i=1}^{\text {lastCDcycle }}\left[\left(U F\left(i \cdot D_{\text {cycle }}\right)-U F\left((i-1) \cdot D_{\text {cycle }}\right)\right) \cdot F C_{C D i}\right]+\left[1-U F\left(R_{C D C}\right)\right] \cdot F C_{C S}
$$

Where $\mathrm{FC}_{\mathrm{UFW}}$ is the utility factor weighted fuel consumption, $U F(D)$ is the utility factor at distance $D \mathrm{~km}, D_{\text {cycle }}$ is the distance for each driving cycle, $F C_{C D i}$ is the fuel consumption in the $i^{\text {th }}$ 
driving cycle, $F C_{C S}$ is the fuel consumption in CS phase, and $R_{C D C}$ is the distance of charge depleting cycle.

The $\mathrm{FC}_{\mathrm{UFW}}$ gives the average fuel consumption of PHEVs, by considering the range distributions. The cycle UF indicates the utility of different ranges in daily use. The utility factor weighted fuel consumptions could be regarded as the average fuel consumption of the PHEV in daily use for the general population.

The $\mathrm{FC}_{\mathrm{UFW}}$ calculated with that (original) utility factor curve is regarded as the national average fuel consumption of the specific PHEV in the U.S, because the utility factor is based on a nation-wide survey. However, this can be extended to any fleet, e.g. taxies, garbage trucks, etc. For different fleets, the daily trip range distribution can be very different. Thus, the utility factor can be customized. Of course, the utility factor can also be updated based on the trip statistics of a single vehicle. Then, the $\mathrm{FC}_{\mathrm{UFW}}$ will indicate the average fuel consumption of that particular vehicle.

From the vehicle owner's perspective, the average fuel consumption is an important part in figuring out the total ownership cost. Thus, it is reasonable and necessary to minimize the average fuel consumption, instead of the fuel consumption of a particular trip, when designing the energy management strategy for the PHEV.

Previous studies usually did not consider the distribution of trip length in designing the EMS. The blended strategy, which almost uniformly utilizes the electricity is only optimal for a given trip with known distance. With the blended strategy, the fuel consumption can be improved by $8 \%$ compared with AECS strategy [7] . However, when considering the distribution of trip length, AECS strategy, which only uses electricity in early stages, benefits the $\mathrm{FC}_{\mathrm{UFW}}$ by increasing the utility of the electricity. It minimizes the electric energy left unused at the end of the trip.

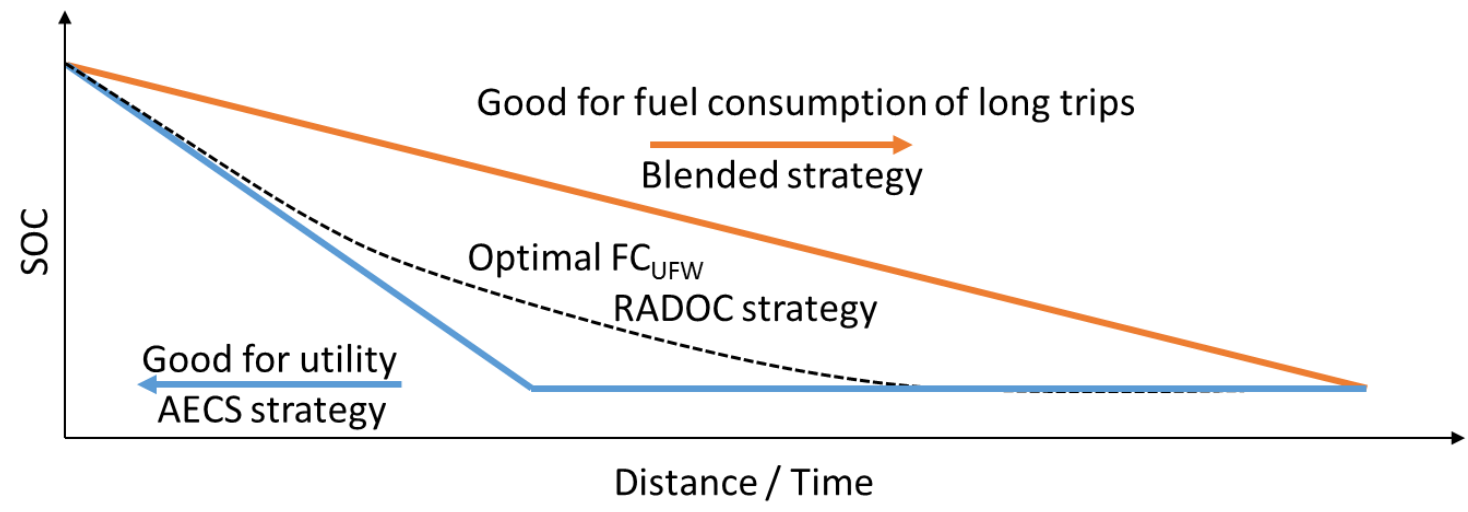

Figure 2. Conceptual sketches of different strategies

In general, the AECS strategy has better electricity utility, while the blended strategy achieves better fuel consumption of long trips. The RADOC strategy must be somewhere in between, illustrated as Figure 2. Intuitively, if a PHEV never travels further than its CD range, AECS is definitely the optimal strategy. And if a PHEV always have long distance travels, the blended is certainly the optimal strategy. But how much should the strategy be blended for unknown trip length? This paper will provide a systematic and quantitative analysis to find out the optimal control strategy with respect to range distributions.

\section{DP Solution}




\subsection{Driving pattern}

The driving pattern session includes the driving cycle and range distribution information used in the DP calculation. There are lots of studies on recognizing the driving cycle in real time [25] Thus, the driving cycle used in the study is constantly the NEDC cycle, which is the official testing cycle used in China. The driving cycle is assumed to be known and fixed in this study and the trips of different length are realized by increasing the number of the same cycle.

The Beijing daily range distribution data from [24] is used. The probability density function of the trip length is shown in Equation 2. In Beijing, the average daily trip length is $37.2 \mathrm{~km}$, most of the trips are under $100 \mathrm{~km} .25 \%$ of the trips are under $12.1 \mathrm{~km}, 50 \%$ of the trips are under 23.9 $\mathrm{km}$ and $80 \%$ of the trips are under $52.5 \mathrm{~km}$. To calculate the UF curve via the original definition, detailed trip lengths are required. However, [24] only provides the trip range distribution. To convert the trip range distribution to a UF curve, the transform equations from the previous study is applied [25] .

$$
\begin{aligned}
p(x) & =\left\{\begin{array}{l}
\frac{\lambda^{\alpha}}{\Gamma(\alpha)} r^{\alpha-1} e^{-\lambda x}, x \geq 0 \\
0, \quad x<0
\end{array}\right. \\
\alpha & =1.2038 \\
\lambda & =0.03588
\end{aligned}
$$

Where the $p(x)$ is the probability density for case that the trip length equals to $x \mathrm{~km}, \alpha$ and $\lambda$ are the parameters of the gamma distribution.

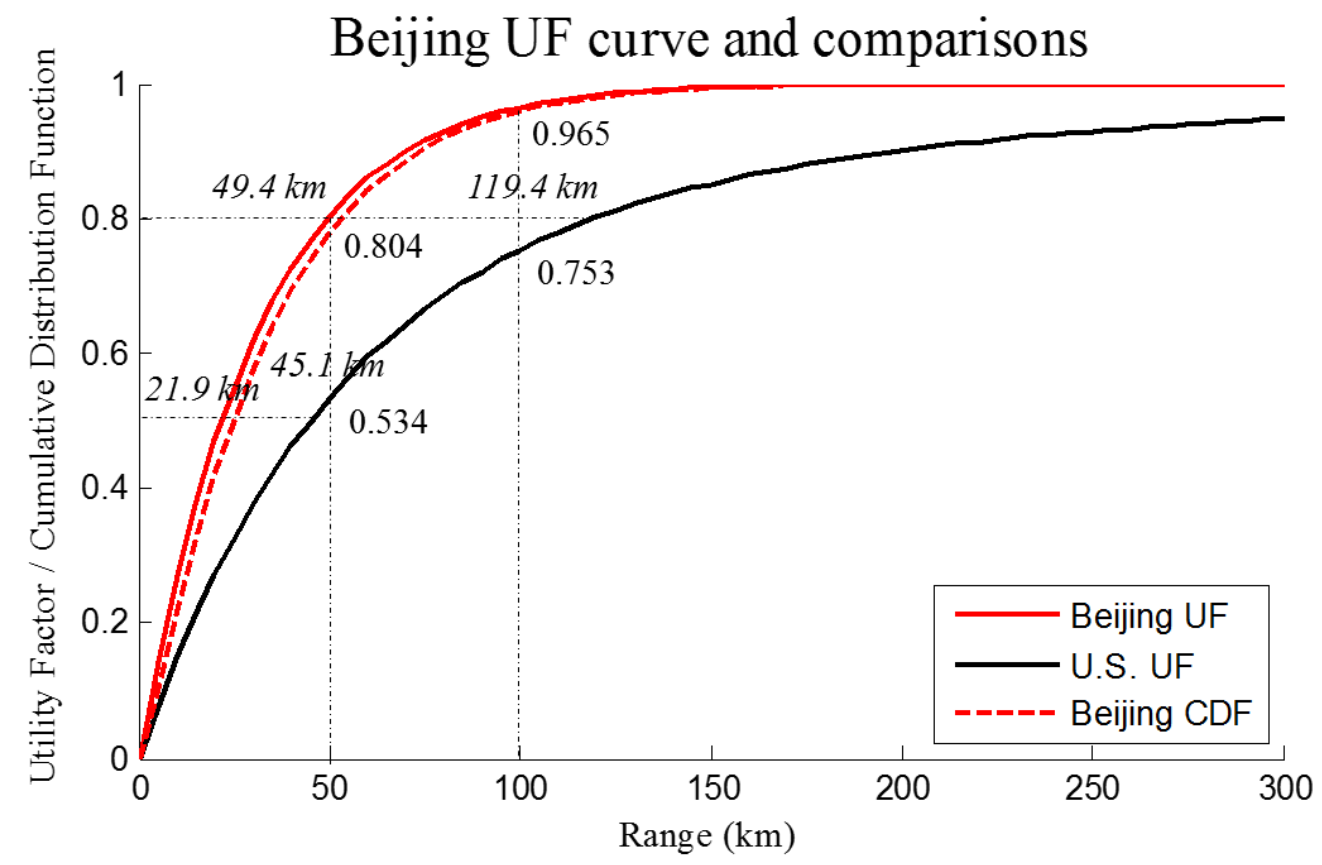

Figure 3. Beijing UF curve compared with the US UF curve

The UF curve of Beijing is plotted in Figure 3. The trip range distribution curve (cumulative distribution function, CDF) is also illustrated by a dashed red curve. Though the difference between the two curves is not large, it is clear the two curves are different, especially for the short range. The UF curve of the US is also shown in Figure 3, based on the data provided in SAE J2841 [21]. We could see the large difference between the two UF curves. In a quantitative 
comparison, for the range of $50 \mathrm{~km}$, the UF of Beijing is 0.80 , while that of US is only 0.53 ; and to electrify $80 \%$ of the travel needs ( $\mathrm{UF}=0.8$ ), the CD range required in the US is $119 \mathrm{~km}$ while that for Beijing is only $49 \mathrm{~km}$.

\subsection{Vehicle model}

The PHEV used in the study is a parallel hybrid vehicle, shown in Figure 4, with a clutch between the engine and the motor, which enables pure electric mode. A quasi-static, backward simulation model is used in this study. As suggested in [9] , the minor transient processes of the dynamics are ignored, because the major concern of this study is the energy management issue.

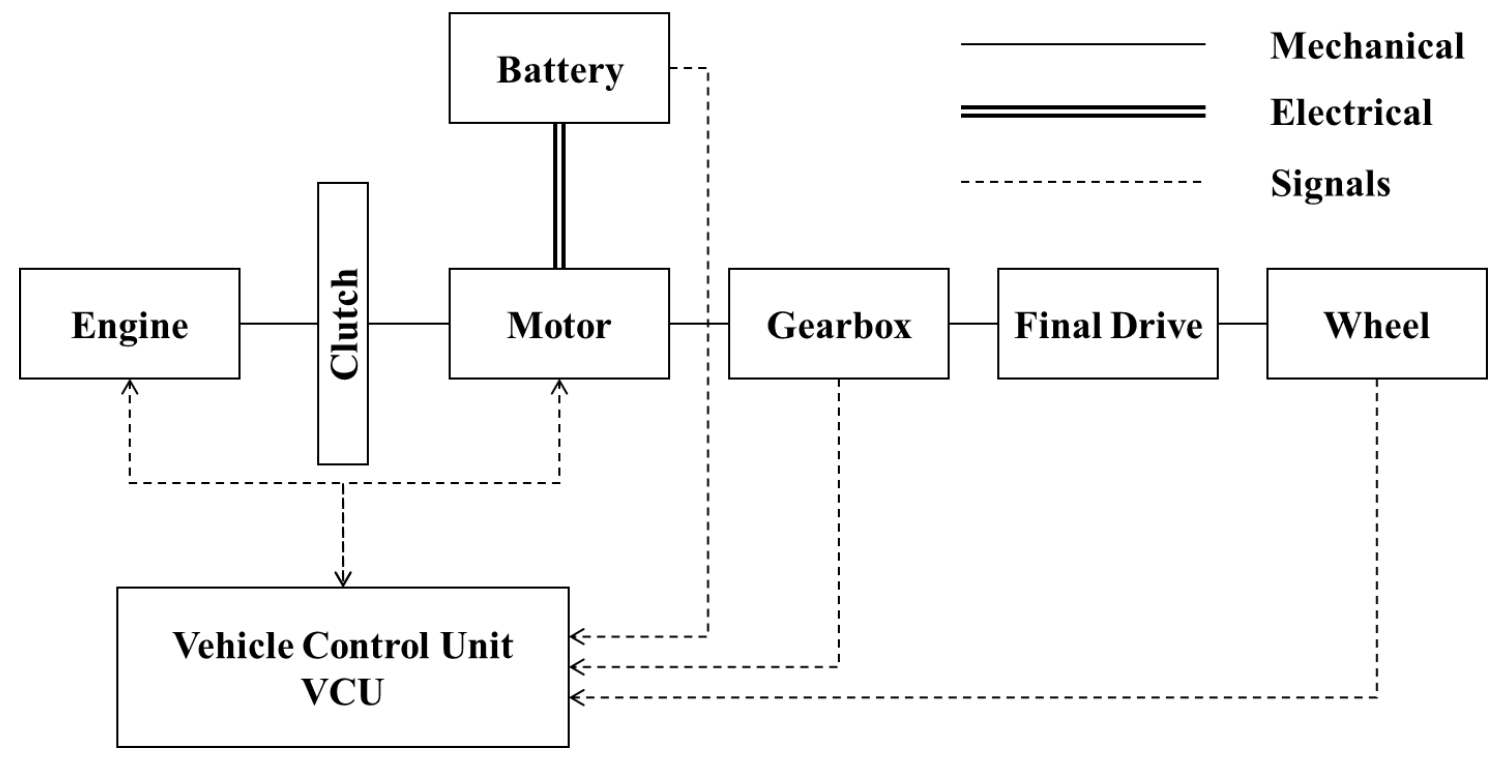

Figure 4. Vehicle powertrain architecture

The engine is a Chinese passenger vehicle engine with the engine efficiency map shown as Figure 5(a). The displacement of the engine is $1.5 \mathrm{~L}$, with a maximum torque of 124 N.m, and maximum power of $63 \mathrm{~kW}$. The engine fuel consumption is obtained from a look-up table. The instantaneous fuel rate is calculated using the engine torque and engine speed. The engine is assumed to shut-down when the engine speed drops below the idle speed.

The motor data is obtained from the Autonomie Software developed by the Argonne National Lab, which has a maximum torque of $458 \mathrm{~N} . \mathrm{m}$ and maximum power of $60 \mathrm{~kW}$. The motor efficiency is also based on a look-up table, shown as Figure 5(b). The efficiency for traction and braking is assumed to be symmetric. For the regenerative brake, only a part of the brake power can be absorbed by the motor. The rest of the brake power is provided by the friction brake. In this study, a constant electric-friction brake force ratio of $8: 2$ is used when the distributed electric power does not exceed its the maximum.

The lithium ion battery is from a pre-production unit tested at the Tsinghua University. The 200-cell battery pack has a total capacity of 2,470 Ah. The cells are grouped into two modules, with 100 cells connected in series in each module. The open circuit voltage of the battery is about $328 \mathrm{~V}$. Thus, the energy capacity is estimated to be $10.57 \mathrm{~kW} . \mathrm{h}$, and the vehicle is roughly classified as a PHEV20. The battery equivalent circuit model is used in the study [9] . Both the open circuit voltage and the internal resistance are considered to be functions of the battery SOC shown as Figure 5(c), constructed using test data.

The gearbox used in the study is an automatic with 4 speeds. The shift strategy is pre-set, and 
regarded as independent from the energy management strategy. The gear shift strategy is only related to the vehicle speed and the acceleration pedal shown as Figure 5(d).

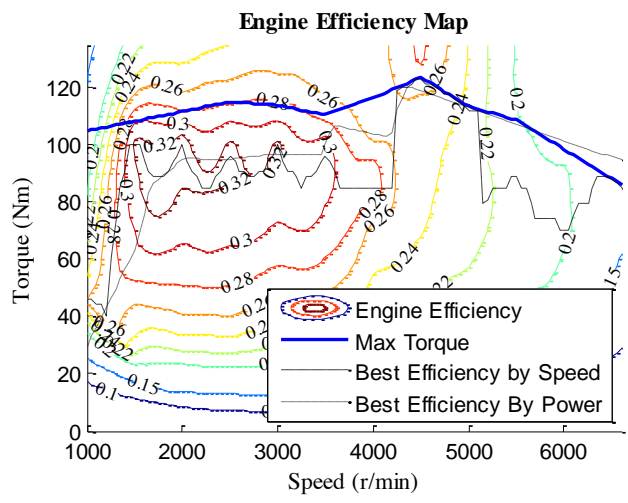

(a) Engine map

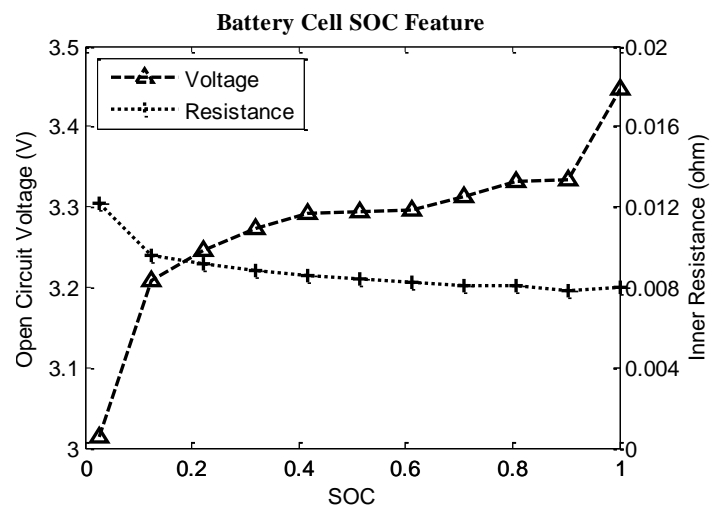

(c) Battery cell SOC feature

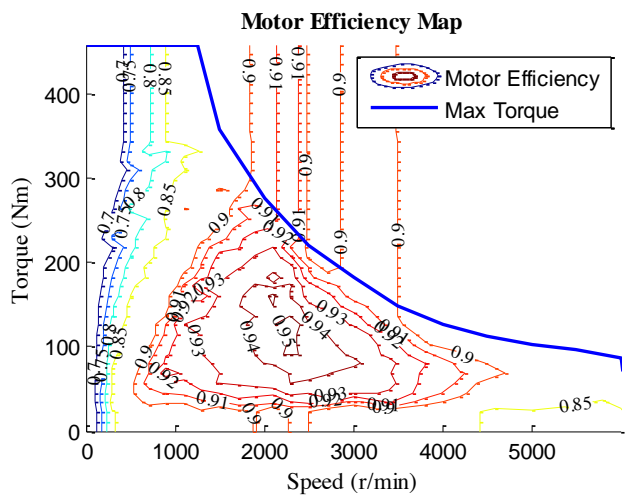

(b) Engine map

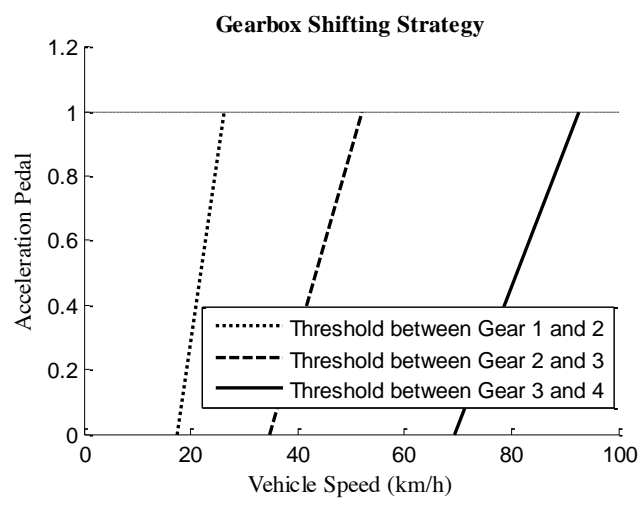

(d) Transmission shift map

Figure 5. Component maps

The final drive ratio is 3.63. Friction loss at the final drive is ignored. The radius of the wheel is $0.301 \mathrm{~m}$. Wheel slip is not considered in this study. The vehicle mass incudes the original vehicle curb mass of $1200 \mathrm{~kg}$ and the battery mass of $79 \mathrm{~kg}$. The fundamental vehicle longitude dynamic equation is used to generate the vehicle speed and vehicle acceleration, shown in Equation 3. The vehicle speed is directly read from the driving schedule.

$$
F_{t}(t)=m_{v} \frac{d}{d t} v(t)+F_{a}(t)+F_{r}(t)+F_{g}(t)
$$

Where $t$ is the current time, $F_{t}$ is traction force required to propel the vehicle, $F_{a}$ is the aerodynamic friction, $F_{r}$ is the rolling friction, $F_{g}$ is the force caused by gravity when driving on non-horizontal roads, $m_{v}$ is the mass of the vehicle and $v$ is the vehicle speed.

The AECS strategy is used as the reference strategy in this study. The PHEV is assumed to start the daily trip fully charged. With the AECS strategy, the battery energy is used exclusively until a SOC threshold is reached. The engine is only used to make up the power gap in extreme situations. During the CS stage, the Equivalent Consumption Minimization Strategy (ECMS) is used to achieve near optimal fuel consumption [8] [27] . The ECMS factor is tuned for the NEDC cycle to achieve SOC sustenance. 


\subsection{Optimization problem}

The dynamic programming (DP) method is used to generate the solution. With DP, the global optimal solution is obtained through backward calculation [28]. The objective function of the optimization problem is the $\mathrm{FC}_{\mathrm{UFw}}$. The original equation is modified as shown in Equation 4. The cycle based equation was transformed from a distance based equation to a time based equation with the assumption of fixed driving cycle. In addition, instead of partitioning the time horizon as "CD + CS", it is now partitioned as "Simulated + Un-simulated". The very long trips are approximated in the simulations because of their low probability of happening. For these long range trips, it is assumed that vehicle operates in CS mode. In this study, we cover $95 \%$ of the total trip length of all trips. For example, the length of the NEDC cycle is $10.93 \mathrm{~km}$. Based on the Beijing's UF curve, it takes 9 cycles $(98.37 \mathrm{~km})$ to cover more than $95 \%$ of the total trip length of all trips.

$$
\begin{aligned}
F C_{U F W} & =\sum_{i=1}^{\text {lass CDcycle }}\left[\left(U F\left(i \cdot D_{\text {cycle }}\right)-U F\left((i-1) \cdot D_{\text {cycle }}\right)\right) \cdot F C_{C D i}\right]+\left[1-U F\left(R_{C D C}\right)\right] \cdot F C_{C S} \\
& =\sum_{i=1}^{\text {lassiscycle }=N}\left[\left(U F\left(i \cdot D_{\text {cycle }}\right)-U F\left((i-1) \cdot D_{\text {cycle }}\right)\right) \cdot F C_{S I M i}\right]+\left[1-U F\left(R_{S I M}\right)\right] \cdot F C_{C S} \\
& =\frac{1}{D_{\text {cycle }}} \cdot \int_{0}^{N \cdot T} U F C(D(t)) \cdot \dot{m}(x, u, t) d t+\left[1-U F\left(R_{S I M}\right)\right] \cdot F C_{C S}
\end{aligned}
$$

Where $N$ is the number of simulation cycles, $F C_{S I M i}$ is the fuel consumption in the $i^{\text {th }}$ simulation cycle, $R_{S I M}$ is the total distance of the simulation cycles, $T$ is the time length for each cycle, $\dot{m}(x, u, t)$ is the engine fuel rate at time $t, \operatorname{UFC}(D)$ is the cycle utility factor at distance $D$ $\mathrm{km}$, and the rest of the symbols have the same definitions as in Equation 1.

As the speed is directly specified by the driving cycle, the PHEV has only one degree of freedom, which is the battery SOC $(x(t))$. The torque split ratio (TSR) is the control variable $(u(t))$. It is defined as the motor torque divided by the total torque at the transmission input. The dynamics can now be described by Equation 5 .

$$
\begin{aligned}
\dot{x}(t) & =f(x, u, t) \\
& =\frac{V_{o c}(x(t))-\sqrt{V_{o c}{ }^{2}(x(t))-4 P_{b a t t}(u(t)) R_{i}(x(t))}}{2 R_{i}(x(t)) Q_{b a t t}}
\end{aligned}
$$

Where $x$ is the battery SOC, $u$ is the torque split ratio, $t$ is the current time, Voc is the open circuit voltage of the battery, $P_{\text {batt }}$ is the output power of the battery, $R_{i}$ is the inner resistance of the battery and $Q_{b a t t}$ is the capacity of the battery.

Both the control variable and the state variable are constrained. For the control variable, it has three limits: the torque envelop curves of both engine and motor, and the power limit of the battery. The battery is limited by the battery terminal voltage. To avoid safety hazards and rapid degradation, the lower and upper limits of individual cells are respectively set to be $2.5 \mathrm{~V}$ and 3.7 V. Besides, the output power should not exceed the battery capability. For the state variable, it must be within the SOC window $\left(x_{\min }, x_{\max }\right)$. The maximum SOC is set to 0.8 , and the sustaining SOC is set to 0.3 [18] . To ensure the final SOC to be around 0.3 , a penalty of SOC lower than 0.3 will be added to the objective function.

The optimization problem is described in Equation 6. The constant multiplier and the 
"un-simulated part" in Equation 4 are omitted because they do not affect the optimization process. A penalty function $h(x)$ for the final SOC is added to ensure fair fuel consumption comparison.

$$
\begin{aligned}
& \min : \int_{0}^{N T} U F C(D(t)) \cdot \dot{m}(x, u, t) d t+h(x(N T)) \\
& \text { s.t. } \\
& \dot{x}(t)=f(x, u, t) \\
& x(t)=\operatorname{SOC}(t), x \in \mathbf{X}=\left\{x \mid x_{\text {min }} \leq x \leq x_{\text {max }}\right\} \\
& 0 \leq T_{\text {eng }} \leq T_{\text {eng } \max } \\
& u(t)=T S R(t), u \in \mathbf{U}=\left\{u \mid T_{\text {mot min }} \leq T_{\text {mot }} \leq T_{\text {mot } \max }\right\} \\
& U_{\text {batt min }} \leq U_{\text {batt }} \leq U_{\text {batt max }}
\end{aligned}
$$

Where $N$ is the number of simulation cycles, $T$ is the time length of each cycle, $U F C(D)$ is the cycle utility factor at distance $D \mathrm{~km}, \dot{m}(x, u, t)$ is the engine fuel rate at time $t$ when the battery SOC is $x$ and the TSR is $u, h(x)$ is the penalty function for final SOC, $x_{\min }$ and $x_{\max }$ are the limit of battery SOC, $T_{e n g}$ and $T_{m o t}$ are respectively the torques delivered by the engine and the motor, and $U_{\text {batt }}$ is the output voltage of the battery.

In the DP optimization, the time horizon, the state space and control space are all discretized, as shown in Figure 6. The time step is selected to be 1 second. The SOC grid is 0.001 . The control grid size is variable during the DP process, depending on the engine, motor and battery constraints. The minimum and maximum TSR will be obtained for each grid. The admissible TSR range is then divided into 100 sub-intervals

The Lagrangian $L_{k}\left(x_{i}, u_{j}\right)$ for time interval $k$, at the state $x_{i}$, with a control decision of $u_{j}$ is:

$$
L_{k}\left(x_{i}, u_{j}\right)=U F C\left(D\left(t_{k}\right)\right) \cdot \dot{m}_{k}\left(x_{i}, u_{j}\right) \cdot \Delta t
$$

The key feature of DP calculation is the concatenate recurrence. For the last step, there is a final SOC penalty function. But the endpoint cost can be considered as part of the cost-to-go for the final SOC grid. Assuming the total number of time steps is $M$, the optimization process at the last time step then follows Equation $8 . J^{*}{ }_{M-1}\left(x_{i}\right)$ is the cost-to-go at $M-1$ time step and $i^{\text {th }}$ SOC grid. $U^{*}{ }_{M-1}\left(x_{i}\right)$ is the optimal control for the state grid $x_{i}$ at time step $M-1, h\left(x_{i}\right)$ is the penalty to the final SOC $x_{i}$, which is calculated from $x_{M-1}$ and $U^{*}{ }_{M-1}\left(x_{i}\right)$.

$$
\begin{aligned}
& J^{*}{ }_{M-1}\left(x_{i}\right)=\min _{u_{j} \in \mathbf{U}}\left[L_{M-1}\left(x_{i}, u_{j}\right)+h\left(x_{i^{\prime}}\right)\right] \\
& u^{*}{ }_{M-1}\left(x_{i}\right)=\underset{u_{j} \in \mathbf{U}}{\operatorname{argmin}}\left[L_{M-1}\left(x_{i}, u_{j}\right)+h\left(x_{i^{\prime}}\right)\right]
\end{aligned}
$$

For time steps 1 to $\mathrm{M}-2$, the process is very similar except that the endpoint penalty is replaced by the cost-to-go function, as illustrated in Equation 9. The cost-to-go function usually needs to be obtained through interpolation because state transition does not always fall onto a grid point.

$$
\begin{aligned}
& J_{k}^{*}\left(x_{i}\right)=\min _{u_{j} \in \mathbf{U}}\left[L_{k}\left(x_{i}, u_{j}\right)+J^{*}{ }_{k+1}\left(x_{i^{\prime}}\right)\right] \\
& u_{k}^{*}\left(x_{i}\right)=\underset{u_{j} \in \mathbf{U}}{\operatorname{argmin}}\left[L_{k}\left(x_{i}, u_{j}\right)+J^{*}{ }_{k+1}\left(x_{i^{\prime}}\right)\right]
\end{aligned}
$$




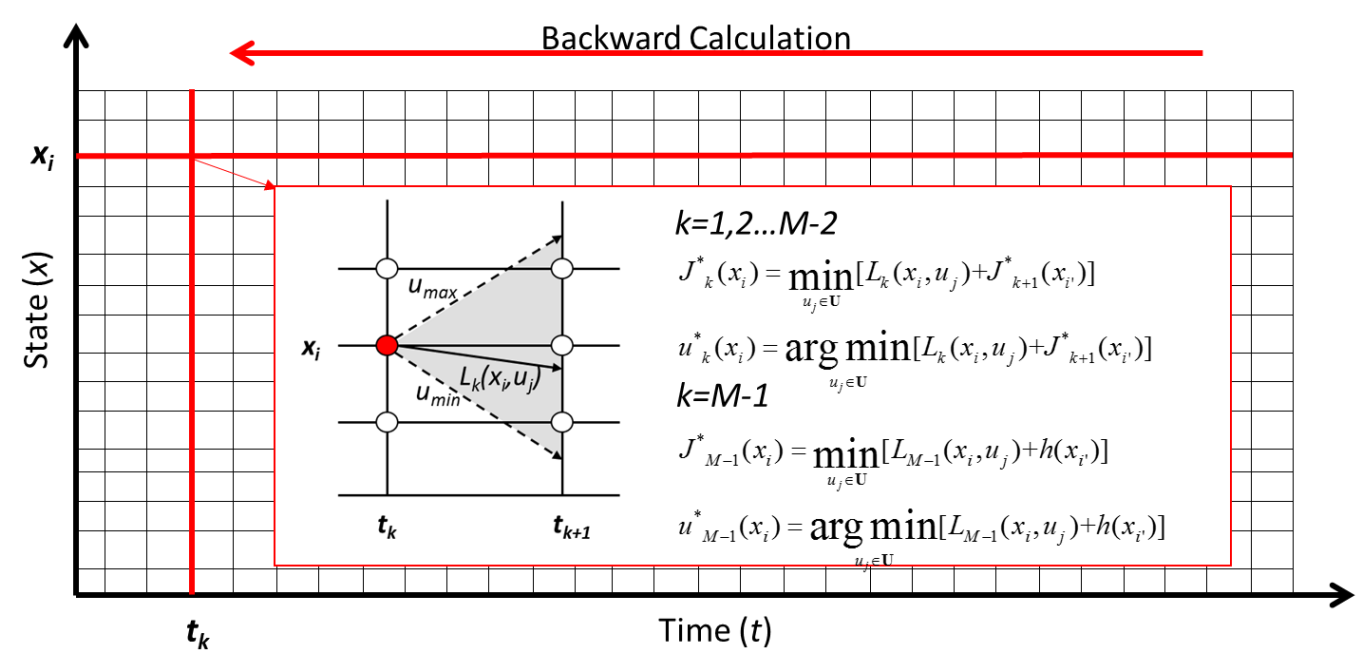

Figure 6. Grids in Dynamic Programming problems

The optimal control trace can be rebuilt by starting from any user defined SOC for any specified time horizon length, by inferring the optimal control and cost-to-go from the stored matrix $J^{*}$ and $u^{*}$ obtained from a DP process solved using the maximum time duration.

\subsection{Calculation results}

Figure 7 and Figure 8 show the calculation results. Figure 7 shows the fuel consumption and utility factor of each cycle. The solid red bars indicate the cycle average fuel consumption using the AECS strategy, while the blue solid bars indicate that using RADOC strategy. The grey curve shows the cycle UF. The hollowed bars show the UF weighted fuel consumption of each cycle. The final $\mathrm{FC}_{\mathrm{UFW}}$ is the summation of the hollow bars, plus the weighted CS fuel consumption. There are almost no differences between the two strategies, except for the $2^{\text {nd }}$ and the $3^{\text {rd }}$ cycles. The RADOC strategy consumes more fuel in the $2^{\text {nd }}$ cycle, and less in the $3^{\text {rd }}$ cycle, compared with the AECS strategy. For all other cycles, the fuel consumptions of the two strategies are nearly the same. This shows that the ECMS strategy is near-optimal for charge sustaining operations and AECS is nearly optimal for the given statistics. Figure 8 shows the corresponding SOC. The results are consistent with the analysis above. At the end of the $2^{\text {nd }}$ cycle, the SOC with AECS strategy stays lower than that with the RADOC strategy, which means the AECS strategy consumes less fuel in the $2^{\text {nd }}$ cycle. During the CS stage, the two SOC traces share a very similar trend, resulting in very similar fuel consumption. 


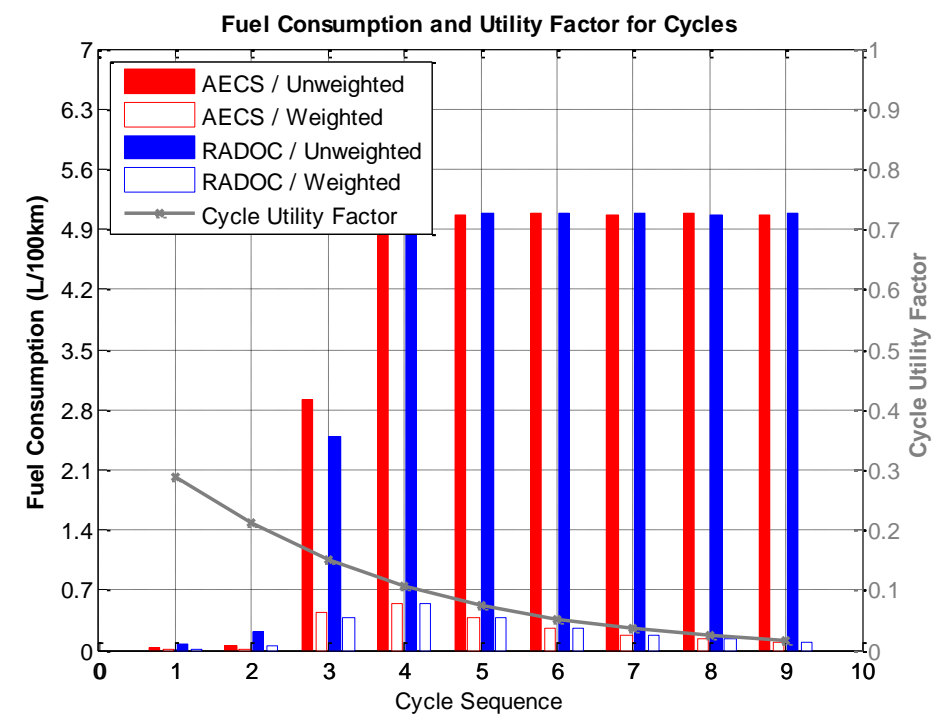

Figure 7. Fuel consumptions and $\mathrm{FC}_{\mathrm{UFW}}$ for each cycle

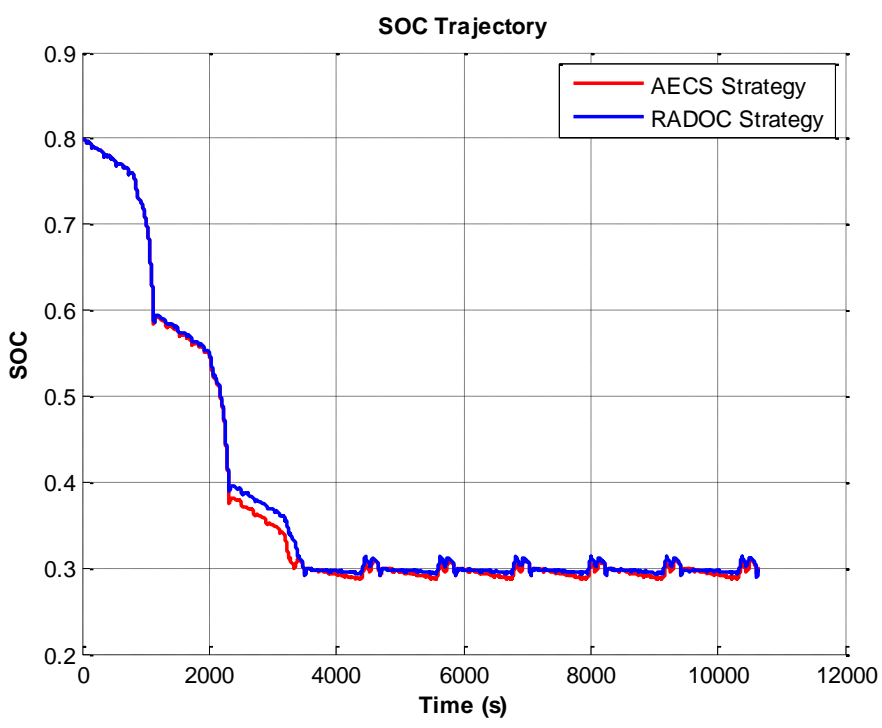

Figure 8. SOC trace comparison

As a summary, the RADOC strategy does improve the $\mathrm{FC}_{\mathrm{UFw}}$. However, the AECS strategy is a near-optimal strategy for PHEV20 if the vehicles are used in Beijing.

\section{Scenario Analysis}

In this section, scenarios with different range distributions, configurations, and driving cycles are analyzed to verify the applicability and performance of the proposed RADOC strategy. Only one factor changes in each scenario.

Figure 9 shows the scenario analysis diagram. The three major factors that affect fuel economy of PHEV are: configuration, driving cycle and range distribution, shown in the top blocks of Figure 9. The configuration diversity (varying battery sizes) will impact the ECMS factor (also referred as SOC-to-fuel conversion factor) used in the CS stage. The range distribution impacts the number of cycles required to cover $95 \%$ of the total trip length of all trips. The driving cycle impacts both on the cycle number required and the ECMS factor. In the calculation of 
$\mathrm{FC}_{\mathrm{UFW}}$ (shown as Equation 4), the fuel consumption in the "simulated" part is related to both cycle number required and the ECMS factor, and the fuel consumption in the "un-simulated" part is only related to the ECMS factor. Thus, in the scenario analysis, if only the cycle number required varies, the un-simulated fuel consumption remains the same in all scenarios. Otherwise, both simulated and un-simulated fuel consumptions should be re-calculated from scenario to scenario. All the results from the above blocks will be gathered into the comparison block, where the RADOC strategy and AECS strategy are compared. Then, by changing only one scenario impact factor at each time, such as the configuration, driving cycle, or range distribution, the results from other scenarios are obtained through the same process. The results of different scenarios will be compared and illustrated in the final block called "scenario analysis".

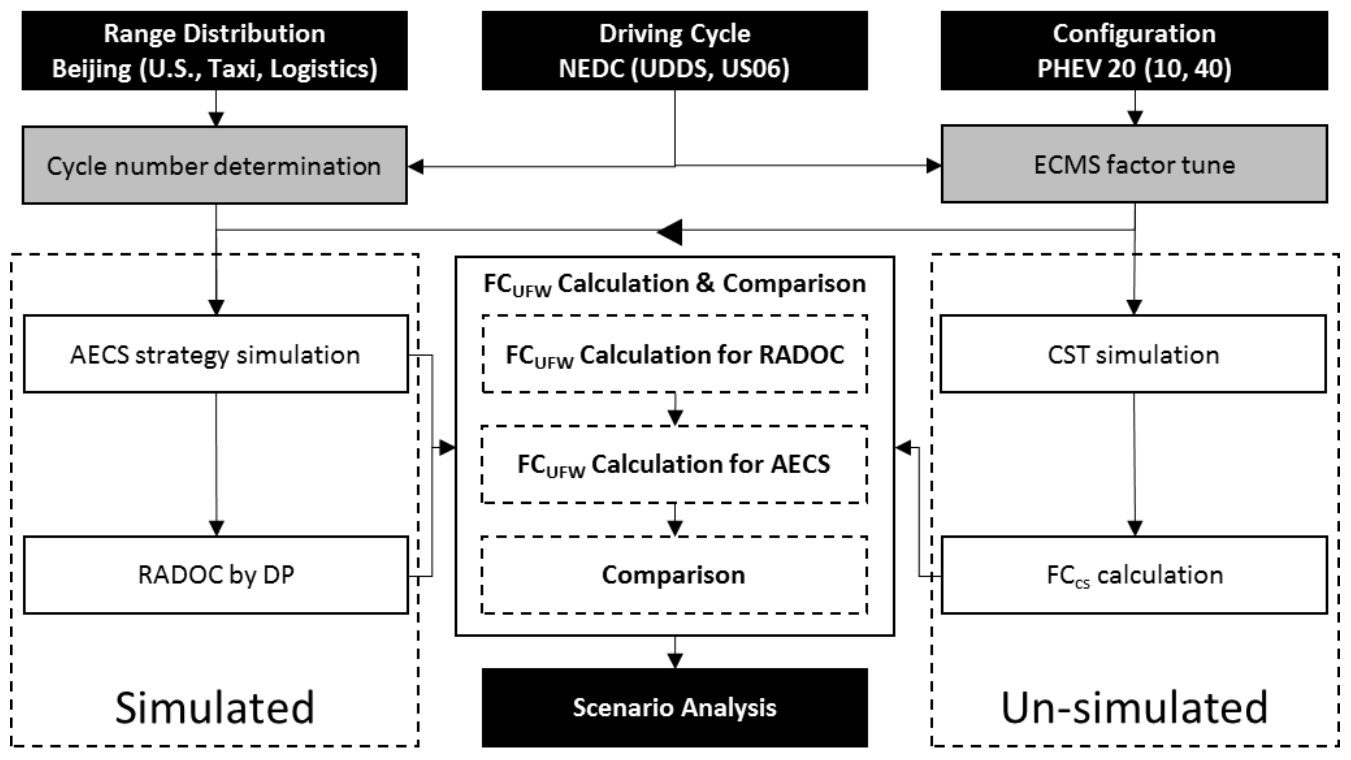

Figure 9. Scenario analysis diagram

\subsection{Different range distribution}

Four different range distributions are used to analyze the $\mathrm{FC}_{\mathrm{UFW}}$ improvement by the RADOC strategy. The Beijing range distribution is from the survey reported in [24] . The trip length distribution follows Equation 2. The U.S. UF curve comes from the SAE J2841 standard [21]. The urban logistics range distribution is based on samples from Beijing, which shows the average daily range of a fleet of urban freight logistics trucks travels is around $100 \mathrm{~km}$. Based on the survey results, we created a normal distribution of the trip length for the urban logistics case. The mean value of the distribution is $100 \mathrm{~km}$, with a standard deviation of $5 \mathrm{~km}$. For the taxi fleet, they travel around $200 \mathrm{~km}$ a day. Another normal distribution is created to describe the trip length distribution of the taxis, where the mean is $200 \mathrm{~km}$ and the standard deviation is $10 \mathrm{~km}$. It should be emphasized again that the UF curve (range distribution) is different and must be derived from the daily trip length distribution. The relationship between the two was reported in [25] .

As Figure 9 shows, the range distribution only impacts the number of cycles required. The number of NEDC cycles required to cover 95\% of the total length of all trips are shown in Table 1. The fuel consumption in the "un-simulated" part stays the same over different range distributions, because of the un-affected ECMS factor.

Simulation results for the four different range distributions show that the RADOC strategy 
improvements vary significantly, as shown in Table 1. The improvements of Beijing and US range distributions are respectively $0.72 \%$ and $0.69 \%$. And those of logistics and taxi range distributions are much higher, $4.06 \%$ and $1.82 \%$, illustrated in Figure 10. From the SOC trace comparison in Figure 11, it is clear that the RADOC strategy is very close to the AECS strategy for the cases with regular range distribution, e.g. Beijing and US. As the utility weighting of the fuel decreases with the increase of trip length, the fuel consumed at short range contributes more to the $\mathrm{FC}_{\mathrm{UFW}}$ than that at long range. As a result, the optimization chooses an AECS-like strategy, suggesting that, for regular range distributions of relatively short trips, the electric utility is much more important than fuel savings for the long trips. For trip populations with longer trips and less uncertainties, such as urban logistics and taxi distributions, the RADOC strategy exhibits a blended behavior. In these distributions, the range is very likely longer than the AER. This results in equal utility weightings for the fuel consumption within that distance, which is illustrated as a straight UF curve shown in Figure 11, where the slope shows the cycle UF weighting.

In summary, for regular range distributions, the RADOC strategy can be approximated by a simple AECS strategy to achieve minimum $\mathrm{FC}_{\mathrm{UFw}}$; for special range distributions with less uncertainty, such as the logistics and taxi fleets, the RADOC strategy will be implemented as a blended strategy.

Table 1. Results of different range distributions

\begin{tabular}{ccccc}
\hline & Beijing & US & Logistics & Taxi \\
\hline Cycles required & 9 & 29 & 9 & 18 \\
\hline AECS (L/100km) & 2.24 & 3.37 & 3.74 & 4.41 \\
\hline RADOC (L/100km) & 2.22 & 3.35 & 3.59 & 4.33 \\
\hline Improvement & $0.72 \%$ & $0.69 \%$ & $4.07 \%$ & $1.82 \%$ \\
\hline
\end{tabular}

Fuel Consumption Improvement by RADOC over different distributions

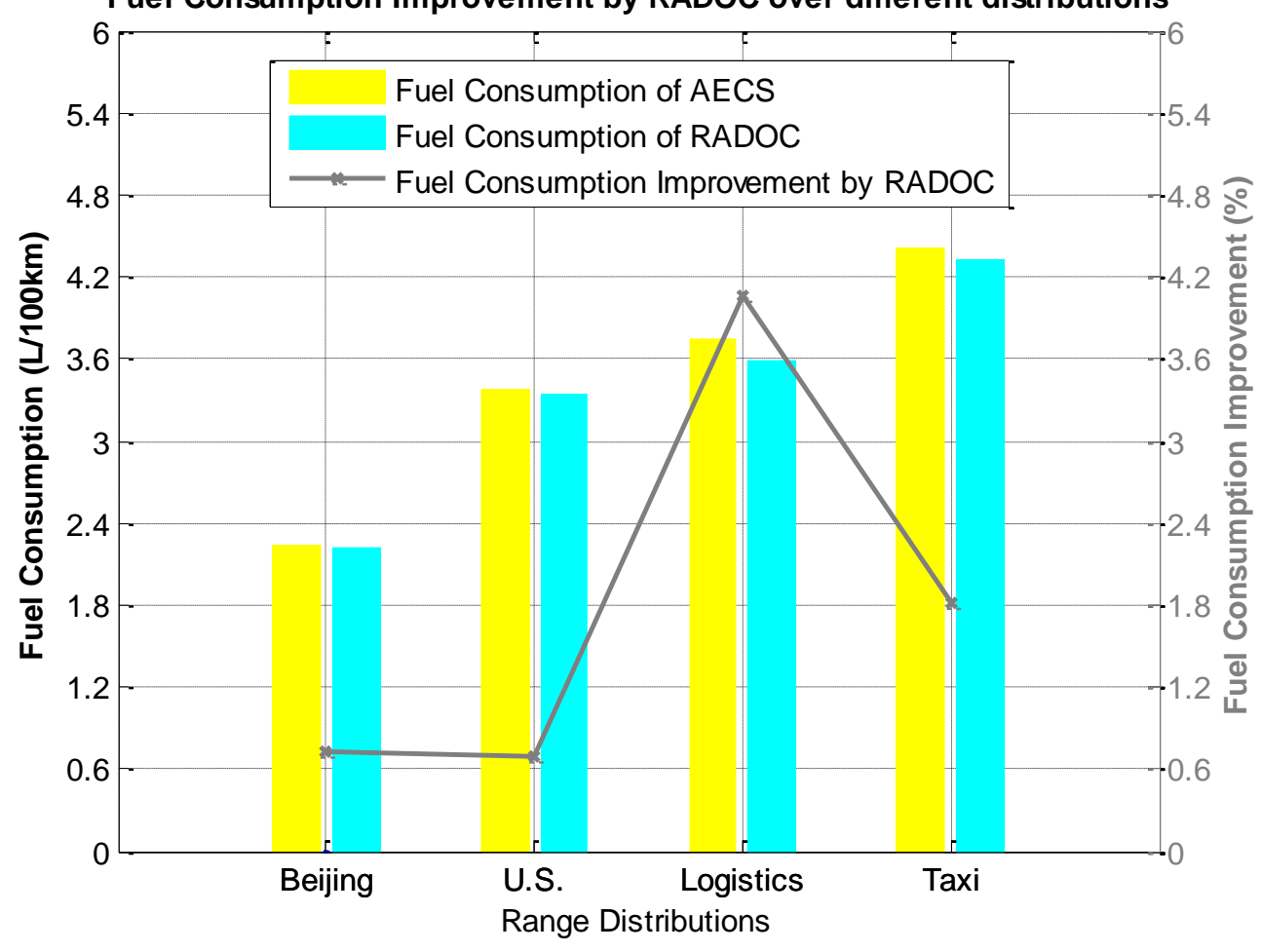

Figure 10. $\quad \mathrm{FC}_{\mathrm{UFW}}$ comparison of different range distributions 

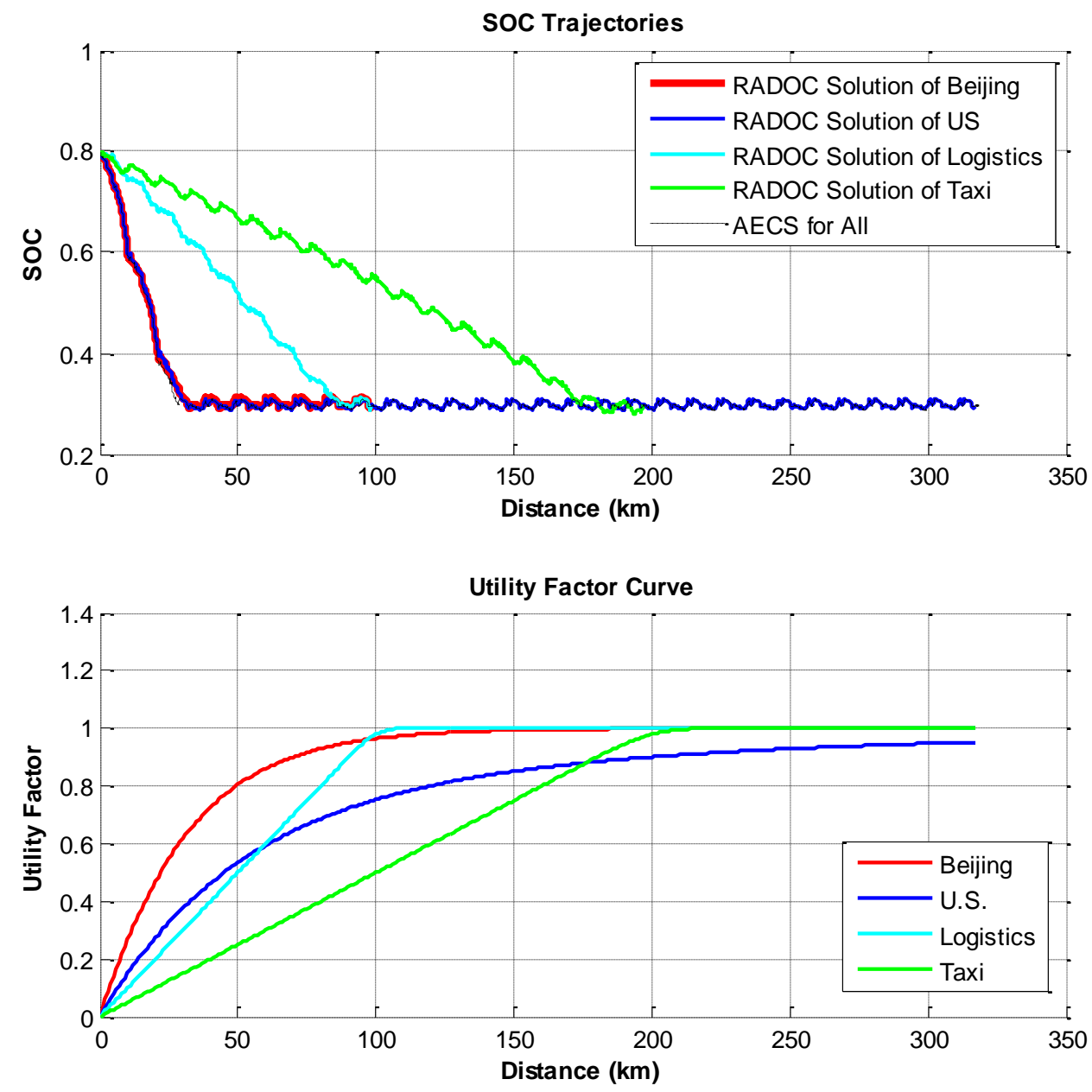

Figure 11. SOC and UF curve comparisons of different range distributions

\subsection{Different configuration}

Three different configurations, including PHEV10, PHEV20, and PHEV40, are used to analyze the $\mathrm{FC}_{\mathrm{UFW}}$ improvement by the RADOC strategy. The only difference between the configurations is the battery size. With the same battery cell model and the same module consisting of 100 cells in series, the PHEV10 has only one module, PHEV20 has two modules connected in parallel, and PHEV40 has four modules connected in parallel. As a result of the arrangement, the nominal open circuit voltages of the three configurations are the same.

The configuration diversity (varying battery sizes) causes the difference in ECMS factor shown as Figure 9. So, the fuel consumptions for both "simulated" and "un-simulated" parts should be re-calculated for every configuration.

The final results are shown in Table 2 and Figure 12. There is an obvious trend that the improvement by RADOC strategy increases with the decrease of battery installed in the PHEV. For PHEV40, the SOC traces with two strategies almost duplicate each other shown in Figure 13. But for PHEV 10, the two traces are apart from each other. This results coincide with the strategies in the product PHEVs. For Prius PHV, it operates in blended mode before the charge is depleted [29] . But for Chevy Volt, it is a typical range extend vehicle, which means it operates exactly as 
an EV whenever there is available electric energy. Speaking of the reason, the electric power from PHEV10 is not large enough to propel the vehicle for some portion of the driving cycle. With the AECS strategy, the engine only supplements the power gap between the demand and the motor. Usually, it is not efficient to do so if the power gap indicates a low load to the engine. Instead, the RADOC strategy will optimally reserve some electricity for this portion of cycle, and distribute a high load to the engine as the engine has to start anyway. This results in a blended use of both electricity and fuel before the CS stage in PHEV10.

As a summary, the RADOC strategy benefits the PHEV with small battery by offering an appropriate blended, regarding the driving range distribution.

Table 2. Results of different configurations

\begin{tabular}{cccc}
\hline & PHEV10 & PHEV20 & PHEV40 \\
\hline Cells in total & 100 & 200 & 400 \\
\hline Cells in series & 100 & 100 & 100 \\
\hline Modules in parallel & 1 & 2 & 4 \\
\hline ECMS factor $(\mathbf{k g})$ & -1.02 & -2.06 & -4.12 \\
\hline CS Fuel Consumption & 5.13 & 5.09 & 5.15 \\
\hline (L/100km) & 3.59 & 2.24 & 0.89 \\
\hline AECS (L/100km) & 3.47 & 2.22 & 0.88 \\
\hline RADOC (L/100km) & $3.30 \%$ & $0.72 \%$ & $0.26 \%$ \\
\hline Improvement & & &
\end{tabular}

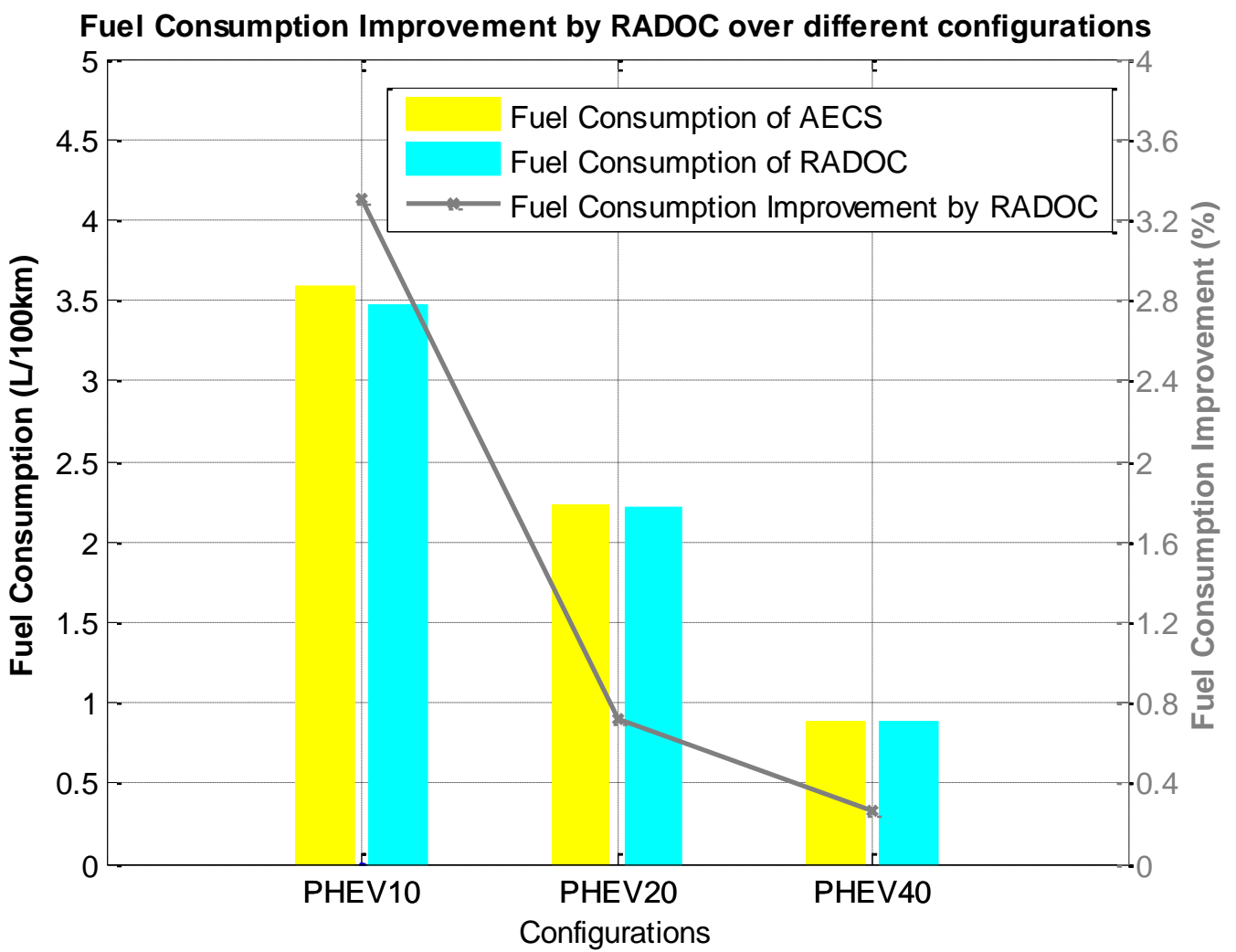

Figure 12. $\quad \mathrm{FC}_{\mathrm{UFW}}$ comparison of different configurations 


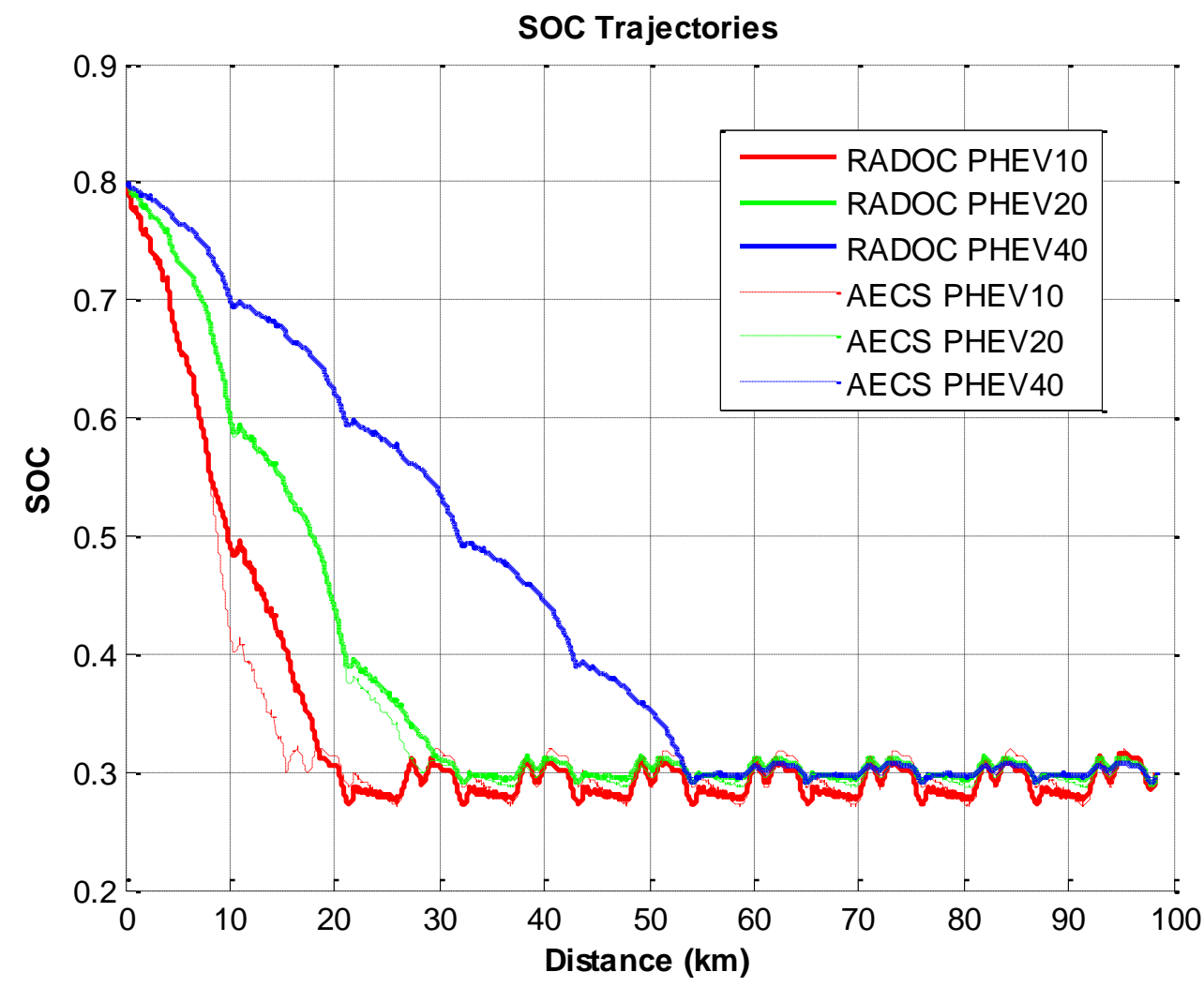

Figure 13. SOC comparison of different configurations

\subsection{Different driving cycles}

Three different driving cycles are included in this analysis. The NEDC cycle used in the base case is regarded as a combined cycle of urban and highway driving. The UDDS cycle is a typical urban driving cycle, while the HFEDS cycle represents the typical highway driving cycle.

As the shown in Figure 9, the driving cycle impacts both on the cycle number required and the ECMS strategy for the CS stage. Thus, in the calculation of $\mathrm{FC}_{\mathrm{UFW}}$, the fuel consumptions of both "simulated" and "un-simulated" parts are different from cycle to cycle.

The analysis result shows that, the improvements brought by RADOC strategy over AECS strategy are all very small - below 1\%, shown in Table 3 and Figure 14. The improvement of the highway driving cycles are higher than that of the urban driving cycle. The SOC trace comparison in Figure 15 shows the difference. For highway driving cycles, there is an obvious blended interval before the charge is completed depleted. The SOC trend verifies the conceptual sketches of this study, shown in Figure 2. For the urban driving cycle, the SOC traces with two strategies almost duplicate, so that the $\mathrm{FC}_{\mathrm{UFW}} \mathrm{S}$ are very close. The SOC trend of the combined driving cycle shows the trend in between the two above, as expected. Because in the blended operations, the engine starts to propel the vehicle in cooperating with the motor. For most of the engines, the efficiency at a high load is better than that at a low load. This is why the more highway driving takes the proportion in a cycle, the more blended the RADOC strategy prefers.

As a summary, although the RADOC strategy is very close to the AECS strategy with all driving cycles, the RADOC strategy works more effectively for highway cycles than for urban cycles. 
Table 3. Results of different driving cycles

\begin{tabular}{cccc}
\hline & NEDC & UDDS & HFEDS \\
\hline Cycle range $(\mathbf{k m})$ & 10.93 & 11.99 & 16.51 \\
\hline Range coverage & & 0.95 & \\
\hline Cycles required & 9 & 8 & 6 \\
\hline ECMS factor(kg) & -2.06 & -2.07 & -1.96 \\
\hline CS Fuel Consumption $(\mathbf{L} / \mathbf{1 0 0} \mathbf{k m})$ & 5.09 & 3.87 & 6.08 \\
\hline AECS $(\mathbf{L} / \mathbf{1 0 0} \mathbf{k m})$ & 2.24 & 1.22 & 3.13 \\
\hline RADOC $(\mathbf{L} / \mathbf{1 0 0 k m})$ & 2.22 & 1.22 & 3.11 \\
\hline Improvement & $0.72 \%$ & $0.10 \%$ & $0.66 \%$
\end{tabular}

Fuel Consumption Improvement by RADOC over different driving cycles

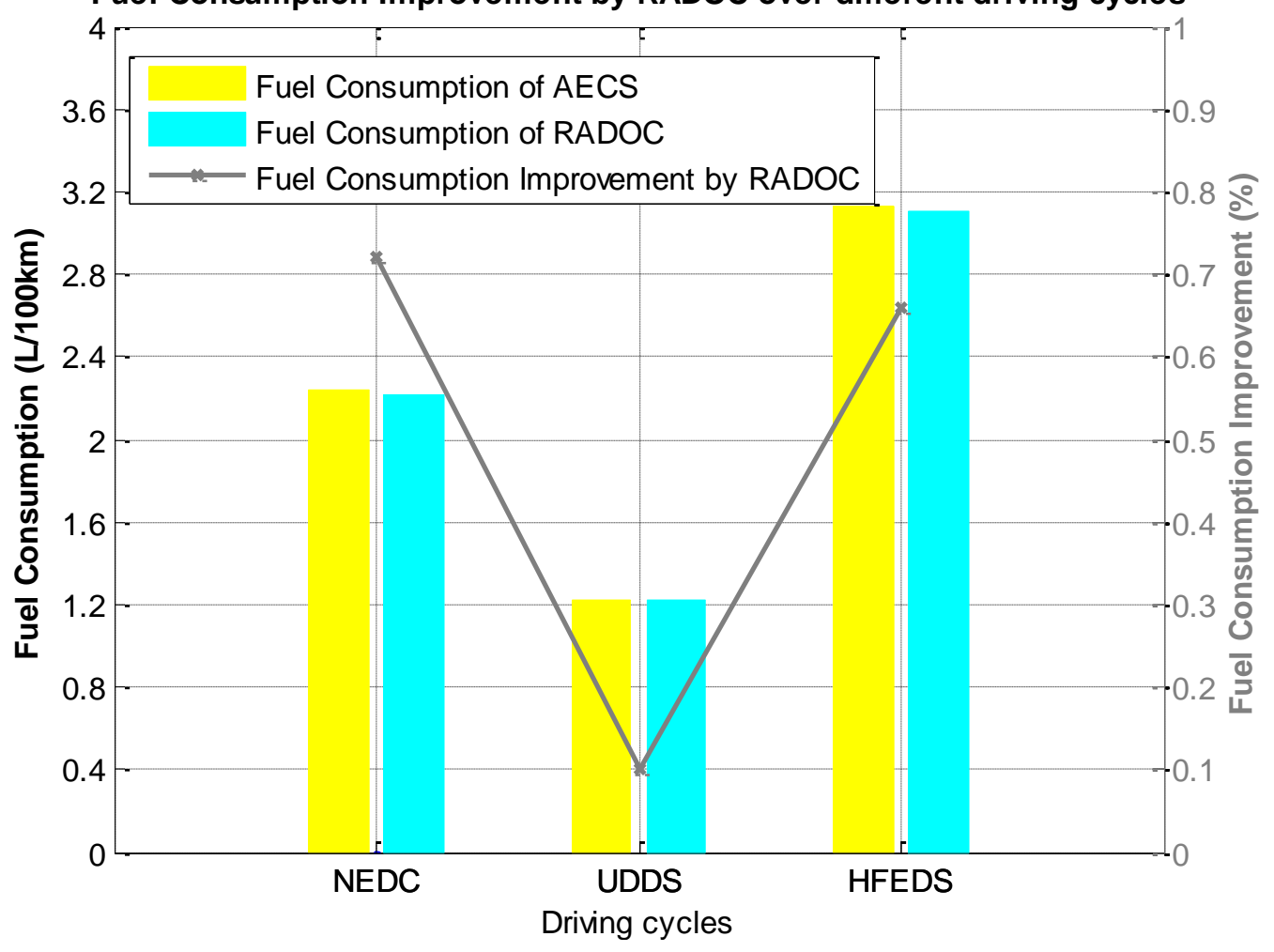

Figure 14. $\quad \mathrm{FC}_{\mathrm{UFW}}$ comparison of different driving cycles 


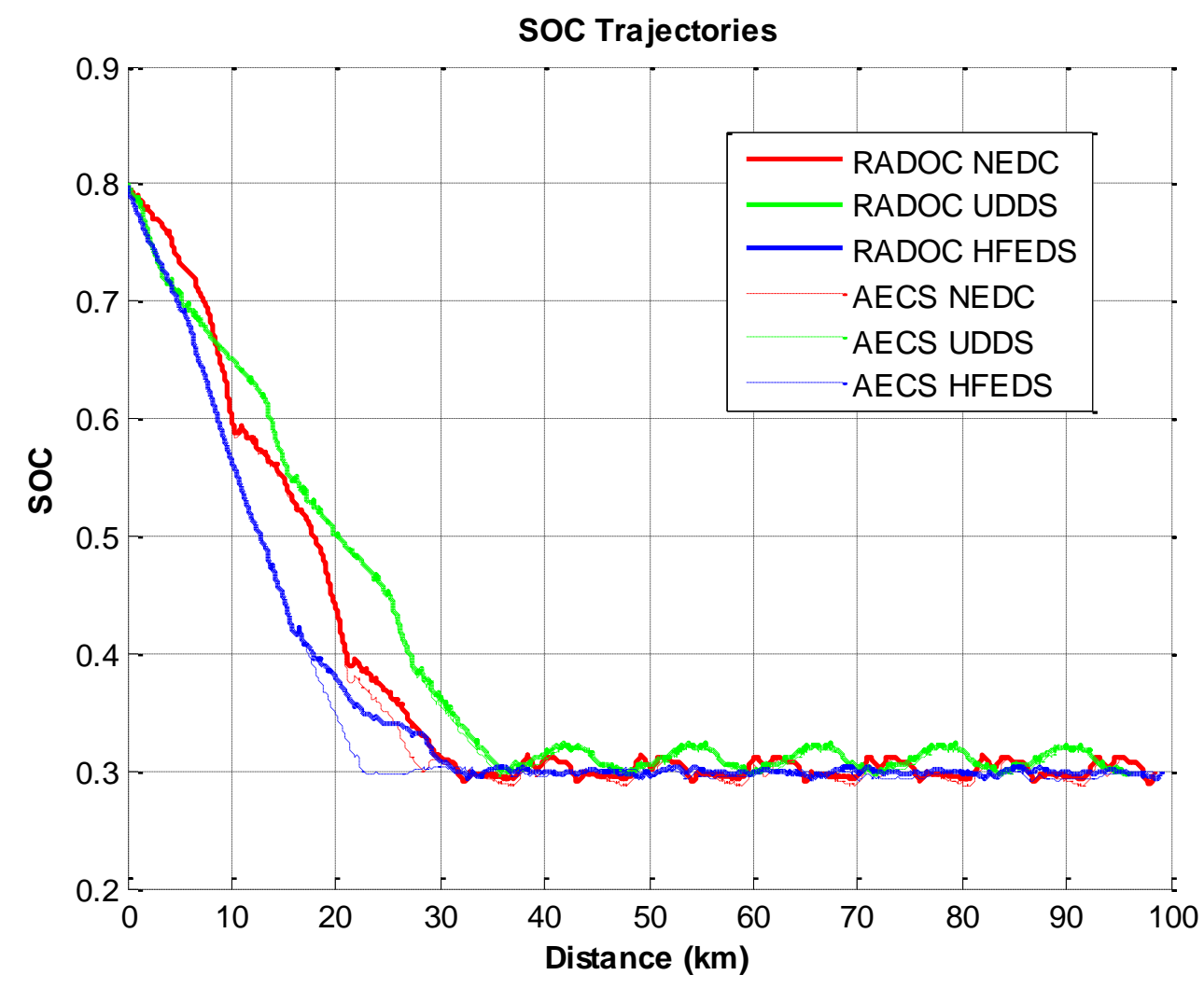

Figure 15. SOC comparison of different driving cycles

\section{Conclusion}

This paper proposes a range adaptive optimal control strategy which minimizes the utility factor weighted fuel consumption $\left(\mathrm{FC}_{\mathrm{UFW}}\right)$. The contributions are summarized as following:

(1) This research proposes a novel idea of minimizing the $\mathrm{FC}_{\mathrm{UFW}}$ in energy management strategy development for PHEVs, as it is a significant factor to evaluate the average fuel consumption of PHEV considering the utility intensity.

(2) The range adaptive optimal control (RADOC) strategy is developed by dynamic programming (DP) to achieve the objective of minimizing the $\mathrm{FC}_{\mathrm{UFW}}$, and it is verified to be available in different scenarios.

(3) According to the scenario analysis: The RADOC strategy can be replaced with AECS strategy when the PHEV is used in regular daily use, while it can be replaced with blended strategy when the PHEV is used as an urban logistics vehicle or a taxi; the RADOC strategy improves more for the PHEV with small batteries than for that with large batteries; and, the RADOC strategy works more effectively in highway driving than in urban driving.

This paper has just verified the necessity of the RADOC strategy via DP. The real-time implementation of RADOC strategy will be studied in the future. After that, the RADOC strategy will be combined with the earlier developed A-PMP strategy [30] to respectively deal with the cases of unknown and known trip length. When the combined strategy is applied to the vehicle, the fuel consumption will be optimized no matter whether the driver inputs the trip length before a trip. If the trip length is given by the driver, the A-PMP strategy will be applied to offer the 
minimum fuel consumption for the coming trip; otherwise, the RADOC strategy will be applied to minimize the $\mathrm{FC}_{\mathrm{UFW}}$ based on the historical trip statistics of the driver.

\section{Acknowledgement}

The collaboration is made possible under the US-China Clean Energy Research Center, a joint center sponsored by China MOST and US DOE. This work is funded by the NSFC (National Natural Science Foundation) of China under the contract of No. 61004075, and the MOST (Ministry of Science and Technology) of China under the contracts of No. 2013BAG16B01 and No. 2010DFA72760.

\section{Reference}

[1] Guang Wu, Xing Zhang, Zuomin Dong, Powertrain architectures of electrified vehicles: review, classification and comparison, Journal of the Franklin Institute, http://dx.doi.org/10.1016/j.jfranklin.2014.04.018

[2] Toyota Prius PHV specifications, http://www.toyota.com/prius-plug-in/\#!/Welcome, 2013.10.20

[3] GM Chevy volt specifications, http://www.chevrolet.com/volt-electric-car.html, 2013.10.20

[4] Ford C-max energi speficifcations, http://www.ford.com/cars/cmax/trim/energi/, 2013.10.20

[5] Gong, Qiuming, Yaoyu Li, and Zhong-Ren Peng. "Optimal power management of plug-in HEV with intelligent transportation system." Advanced intelligent mechatronics, 2007 IEEE/ASME international conference on. IEEE, 2007.

[6] Honarmand, Masoud, Alireza Zakariazadeh, and Shahram Jadid. "Self-scheduling of electric vehicles in an intelligent parking lot using stochastic optimization." Journal of the Franklin Institute (2014). http://dx.doi.org/10.1016/j.jfranklin.2014.01.019

[7] Sanjaka G. Wirasingha, Ali Emadi, Classification and Review of Control Strategies for Plug-In Hybrid Electric Vehicles, IEEE Transaction on vehicular technology, VOL. 60, NO. 1, JANUARY 2011, 111-122

[8] Serrao, Lorenzo. A comparative analysis of energy management strategies for hybrid electric vehicles. Diss. Ohio State University, 2009.

[9] Guzzella, Lino, and Antonio Sciarretta. Vehicle propulsion systems. Springer, 2007.

[10] Banvait, Harpreetsingh, Sohel Anwar, and Yaobin Chen. A rule-based energy management strategy for plug-in hybrid electric vehicle (PHEV). In American Control Conference, 2009. ACC'09., pp. 3938-3943. IEEE, 2009.

[11] Montazeri-Gh, Morteza, Amir Poursamad, and Babak Ghalichi. Application of genetic algorithm for optimization of control strategy in parallel hybrid electric vehicles. Journal of the Franklin Institute 343.4 (2006): 420-435.

[12] Cong HOU, Minggao OUYANG, Hewu WANG, Liangfei XU, An assessment of PHEV energy management strategies using driving range data collected in Beijing, EVS27 International Battery, Hybrid and Fuel Cell Electric Vehicle Symposium, NOV, 2013.

[13] Kum, Dongsuk, Huei Peng, and Norman Bucknor. Optimal control of plug-in HEVs for fuel economy under various travel distances. Advances in Automotive Control. 2010.

[14] Karbowski, Dominik, S. Pagerit, J. Kwon, A. Rousseau, and K. Pechmann. Fair comparison 
of powertrain configurations for plug-in hybrid operation using global optimization. In SAE World Congress, Detroit SAE paper, pp. 01-1334. 2009.

[15] Lai L, Ehsani M. Dynamic Programming Optimized Constrained Engine on and off Control Strategy for Parallel HEV[C]//Vehicle Power and Propulsion Conference (VPPC), 2013 IEEE. IEEE, 2013: 1-5.

[16] Kim, Namwook, Sukwon Cha, and Huei Peng. Optimal control of hybrid electric vehicles based on Pontryagin's minimum principle. Control Systems Technology, IEEE Transactions on 19.5 (2011): 1279-1287.

[17] Kim, Namwook, Aymeric Rousseau, and Daeheung Lee. A jump condition of PMP-based control for PHEVs. Journal of Power Sources 196.23 (2011): 10380-10386.

[18] Gong, Qiuming, Yaoyu Li, and Zhong-Ren Peng. Trip based power management of plug-in hybrid electric vehicle with two-scale dynamic programming. Vehicle Power and Propulsion Conference, 2007. VPPC 2007. IEEE. IEEE, 2007.

[19] Kum, Dongsuk, Huei Peng, and Norman K. Bucknor. "Optimal energy and catalyst temperature management of plug-in hybrid electric vehicles for minimum fuel consumption and tail-pipe emissions." Control Systems Technology, IEEE Transactions on 21.1 (2013): 14-26.

[20] Duoba, Michael. Evaluating PHEV technology using component HIL, subsystem, and chassis dynamometer testing: methods and results. SAE Hybrid Vehicle Technologies 2007 Symposium. 2007.

[21] SAE International, Utility Factor Definitions for Plug-In Hybrid Electric Vehicles Using 2001 U.S. DOT National Household Travel Survey Data. SAE J2841 [S] MAR, 2009.

[22] National Household Travel Survey official website, http://nhts.ornl.gov/, 2013.10.20

[23] SAE International, Recommended Practice for Measuring the Exhaust Emissions and Fuel Economy of Hybrid-Electric Vehicles, Including Plug-in Hybrid Vehicles SAE J1711 [S] JUN, 2010.

[24] Lvwei Wu, A GPS-based Research on the Driving Patterns of Private Passenger Vehicle in Beijing. Diss. Tsinghua University, 2013.

[25] Xing Zhang, Guang Wu, Zuomin Dong, Curran Crawford, Embedded feature-selection support vector machine for driving pattern recognition, Journal of the Franklin Institute, http://dx.doi.org/10.1016/j.jfranklin.2014.04.021

[26] Cong Hou, Hewu Wang \& Minggao Ouyang, A methodology of calculating PHEV average fuel consumption based on the trip range distribution, Automotive Engineering, In Press, 2013.

[27] Sciarretta, Antonio, and Lino Guzzella. Control of hybrid electric vehicles. Control systems, IEEE 27.2 (2007): 60-70.

[28] Kirk, Donald E. Optimal control theory: an introduction. DoverPublications. com, 2012.

[29] Carlson, Richard W., Michael J. Duoba, Theodore P. Bohn, and Anantray D. Vyas , Testing and analysis of three plug-in hybrid electric vehicles. SAE International, 2007.

[30] Hou, Cong, Ouyang, Minggao, Xu, Liangfei, and Wang Hewu. Approximate Pontryagin's minimum principle applied to the energy management of plug-in hybrid electric vehicles. Applied Energy 115 (2014): 174-189. 


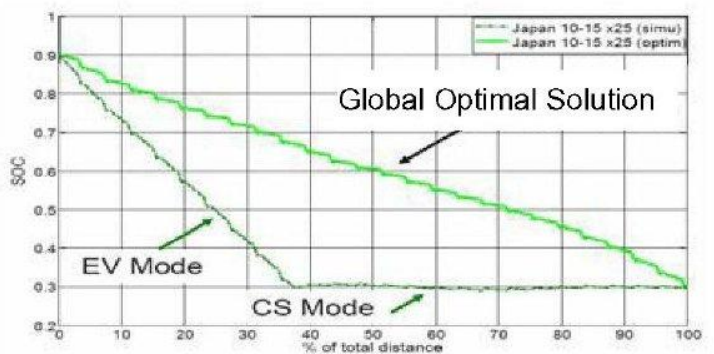

(a) SOC Profile

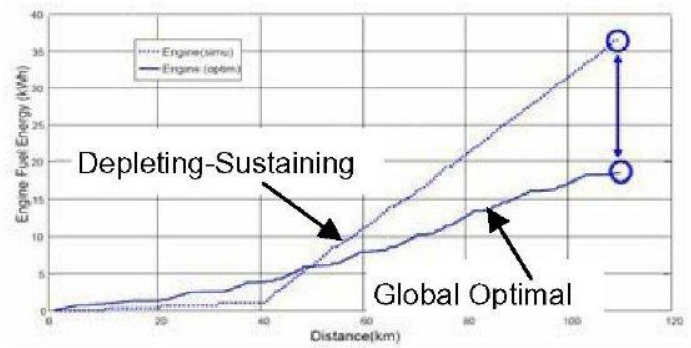

(b) Fuel Consumption

Figure 1. PHEV power management using global optimization method

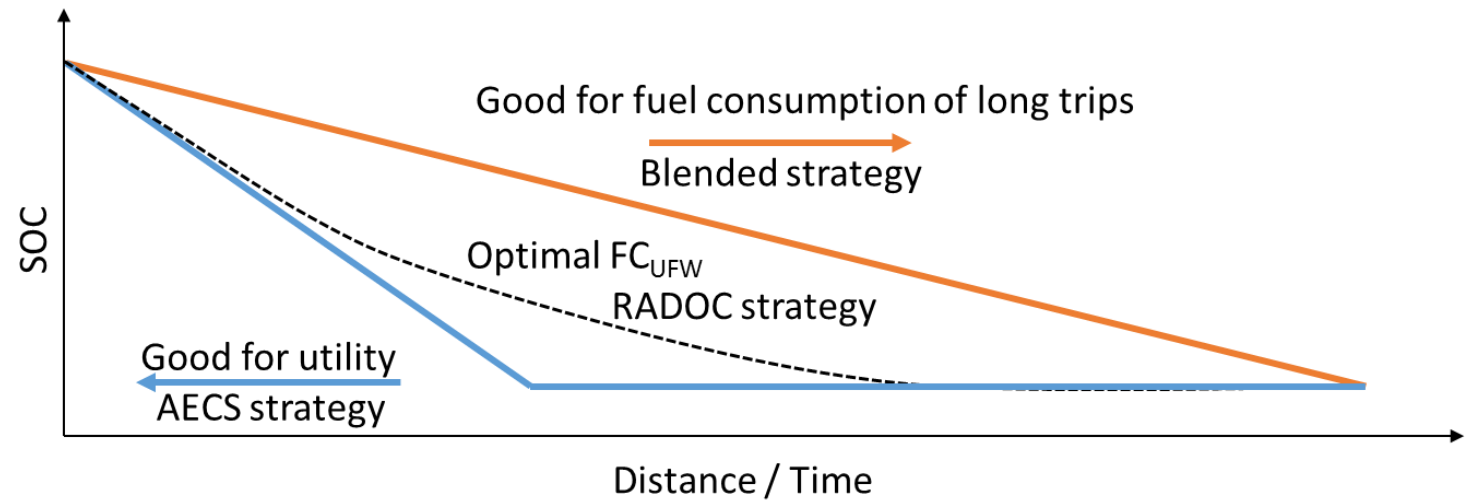

Figure 2. Conceptual sketches of different strategies 


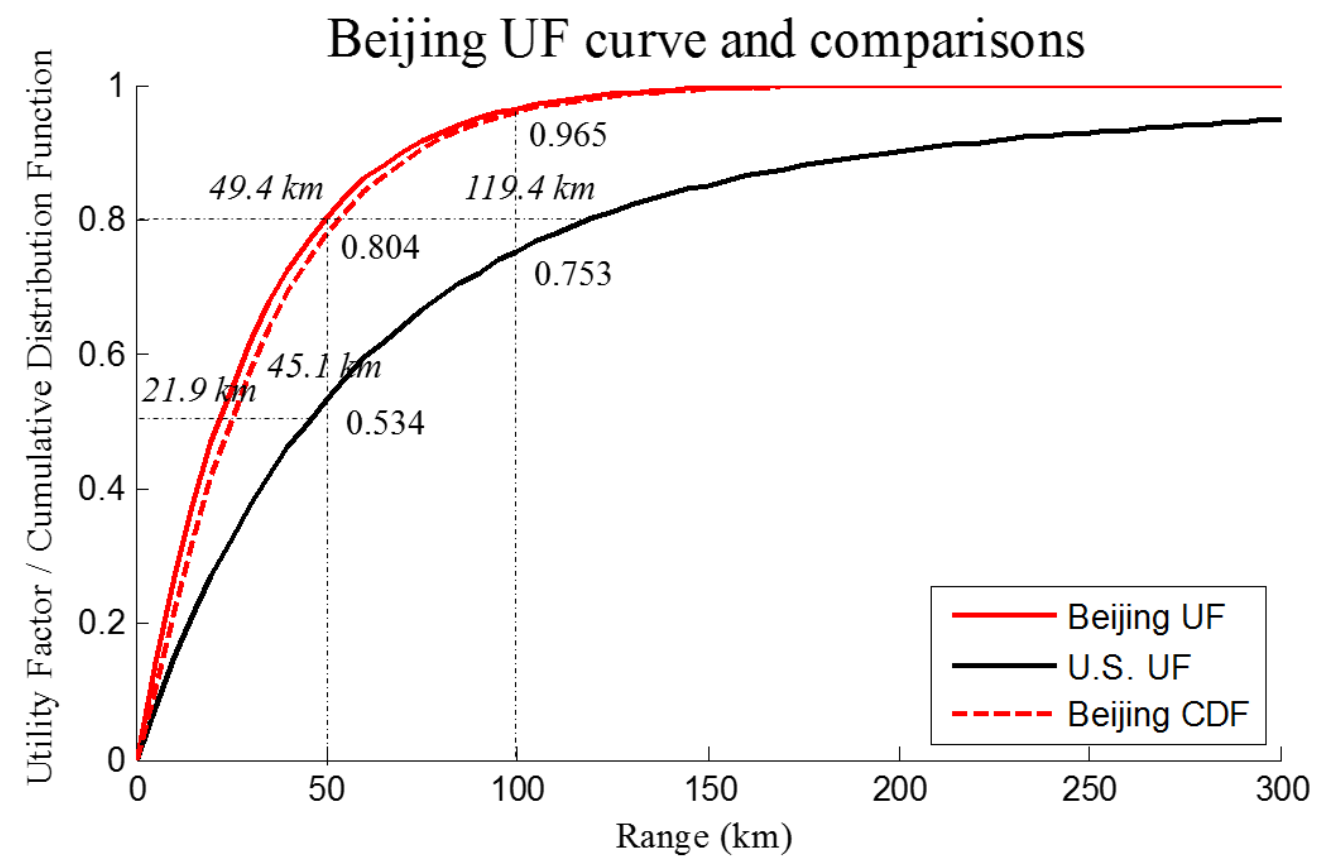

Figure 3. Beijing UF curve compared with the US UF curve

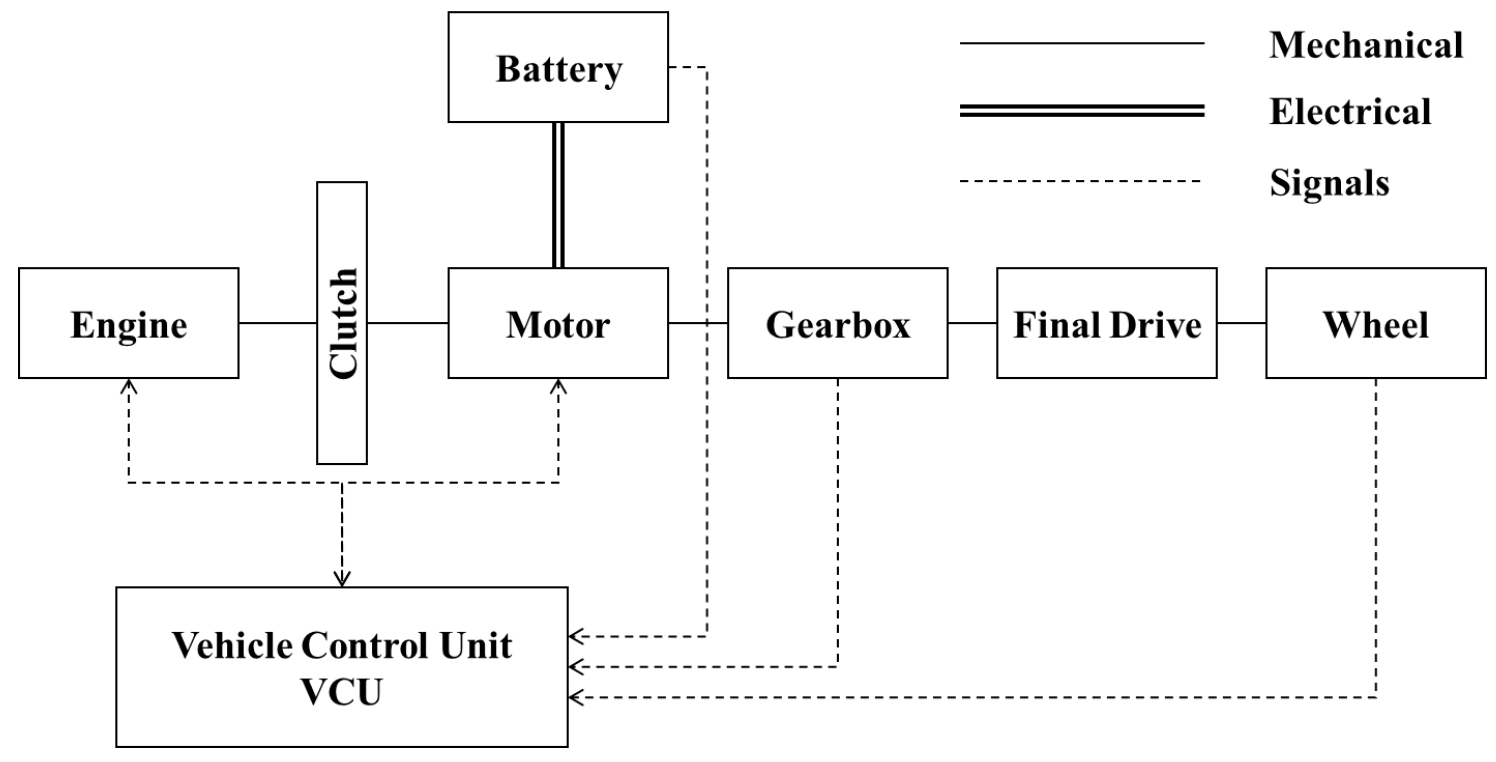

Figure 4. Vehicle powertrain architecture 


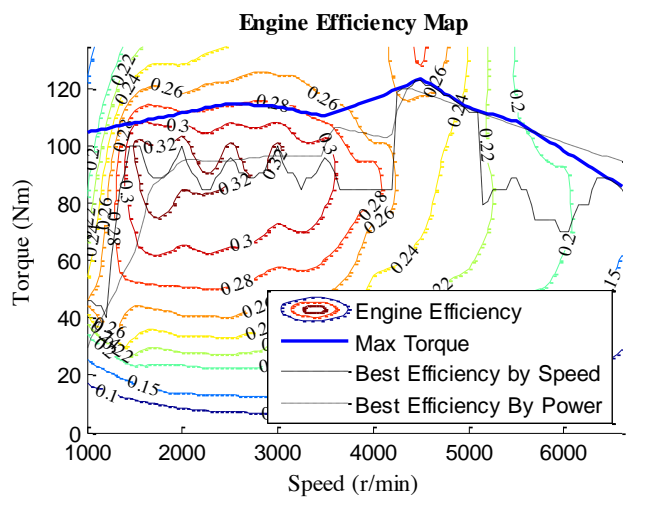

(a) Engine map

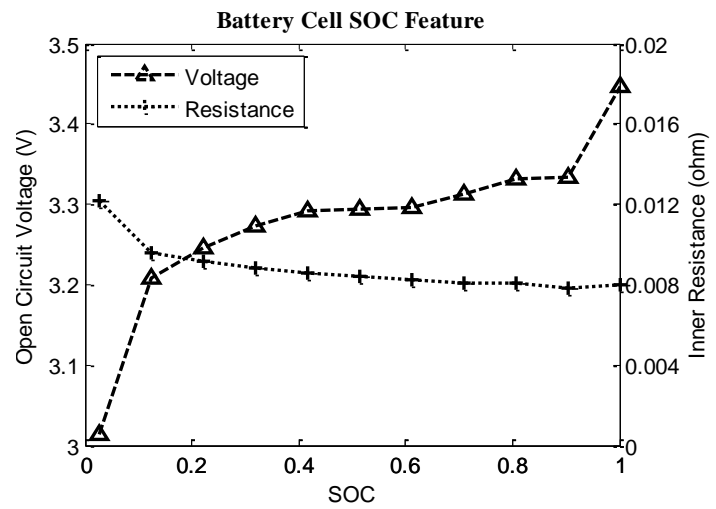

(c) Battery cell SOC feature

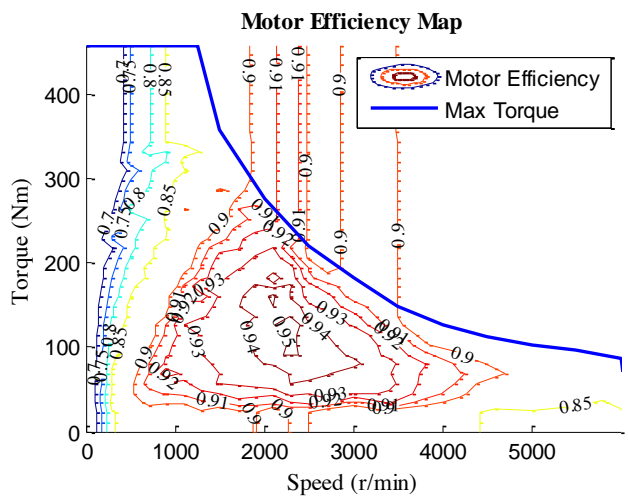

(b) Engine map

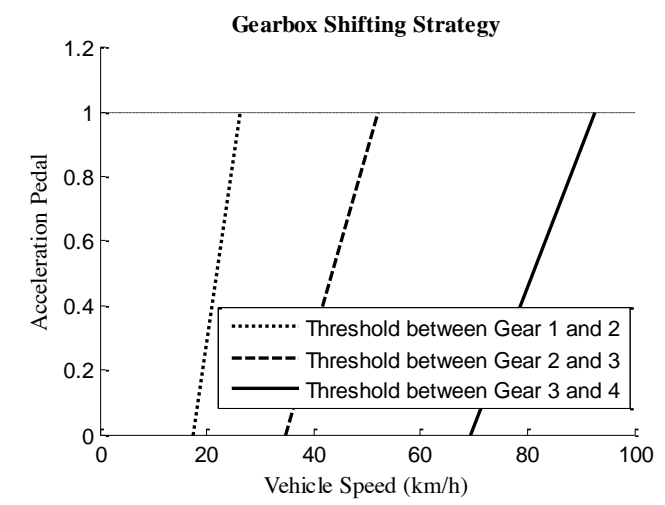

(d) Transmission shift map

Figure 5. Component maps

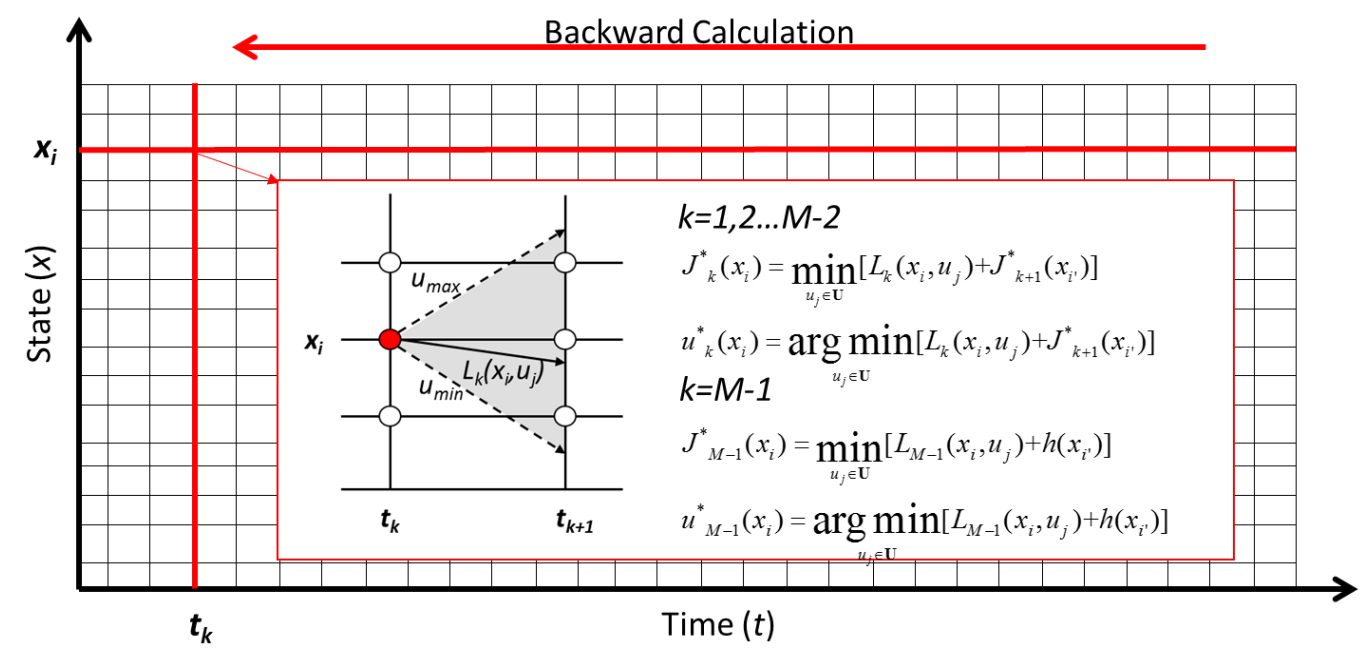

Figure 6. Grids in Dynamic Programming problems 


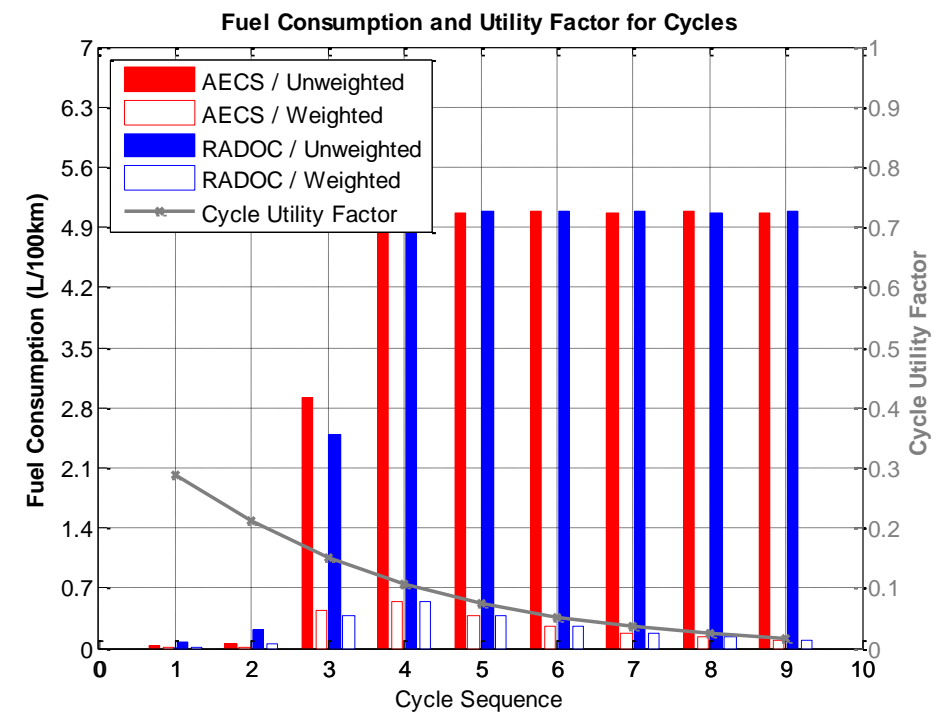

Figure 7. Fuel consumptions and $\mathrm{FC}_{\mathrm{UFW}}$ for each cycle

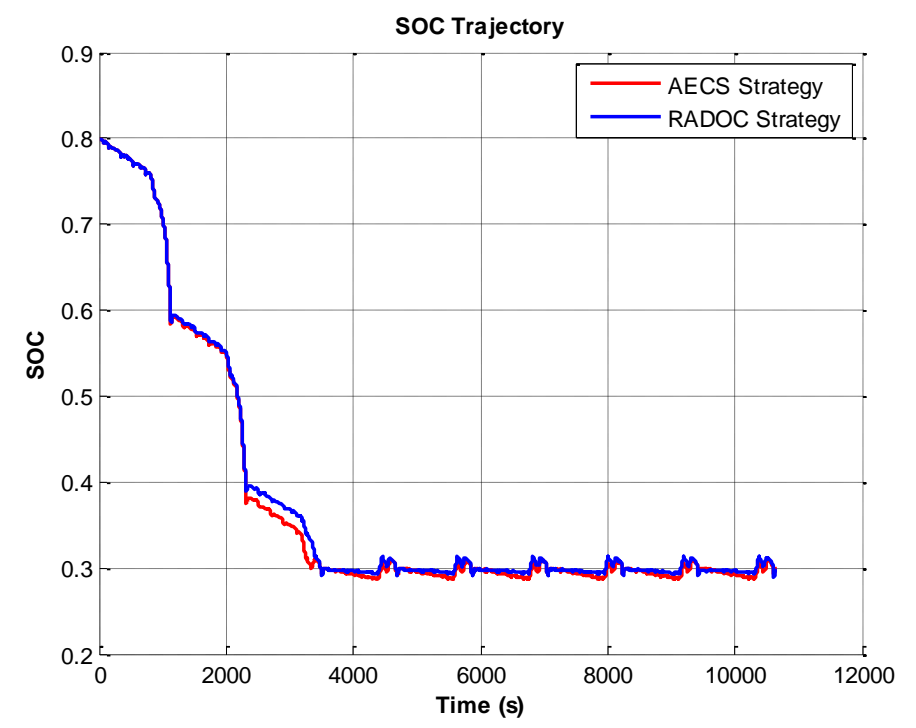

Figure 8. SOC trace comparison 


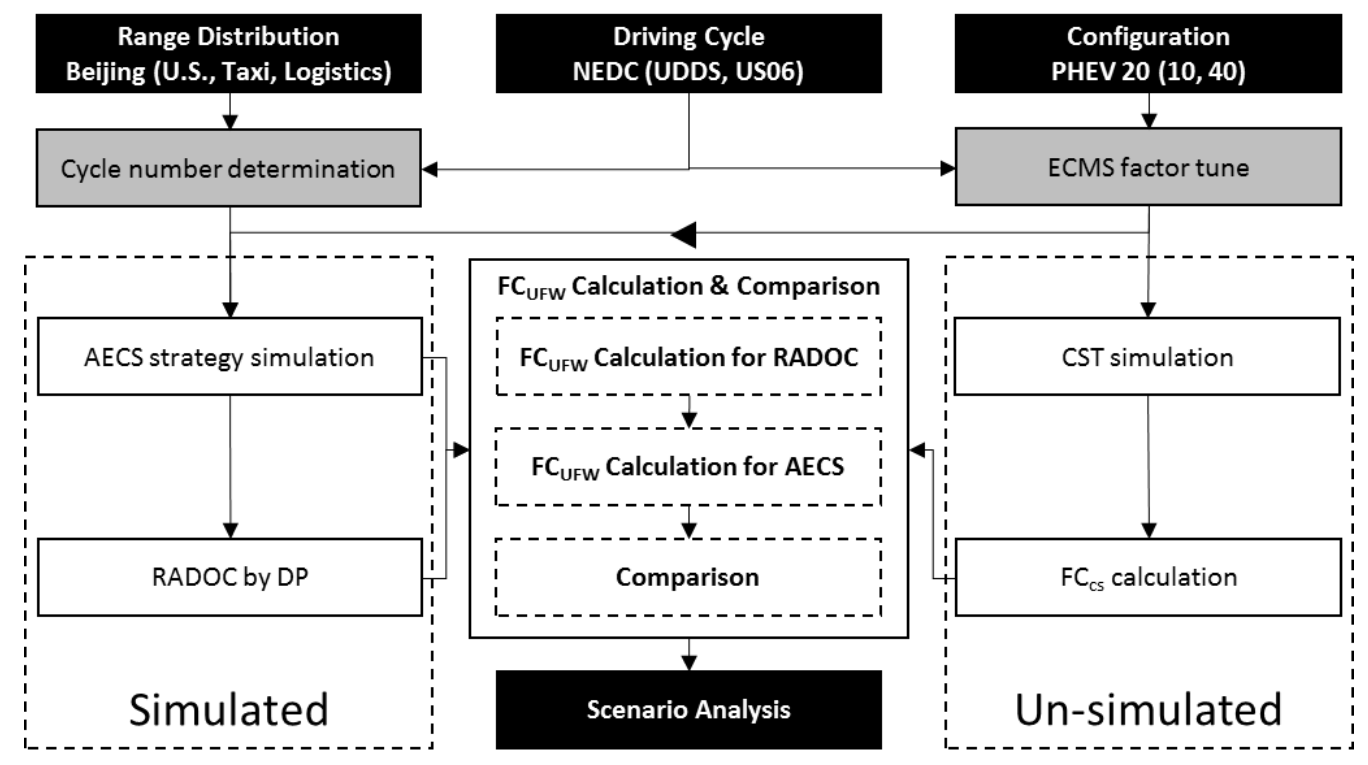

Figure 9. Scenario analysis diagram

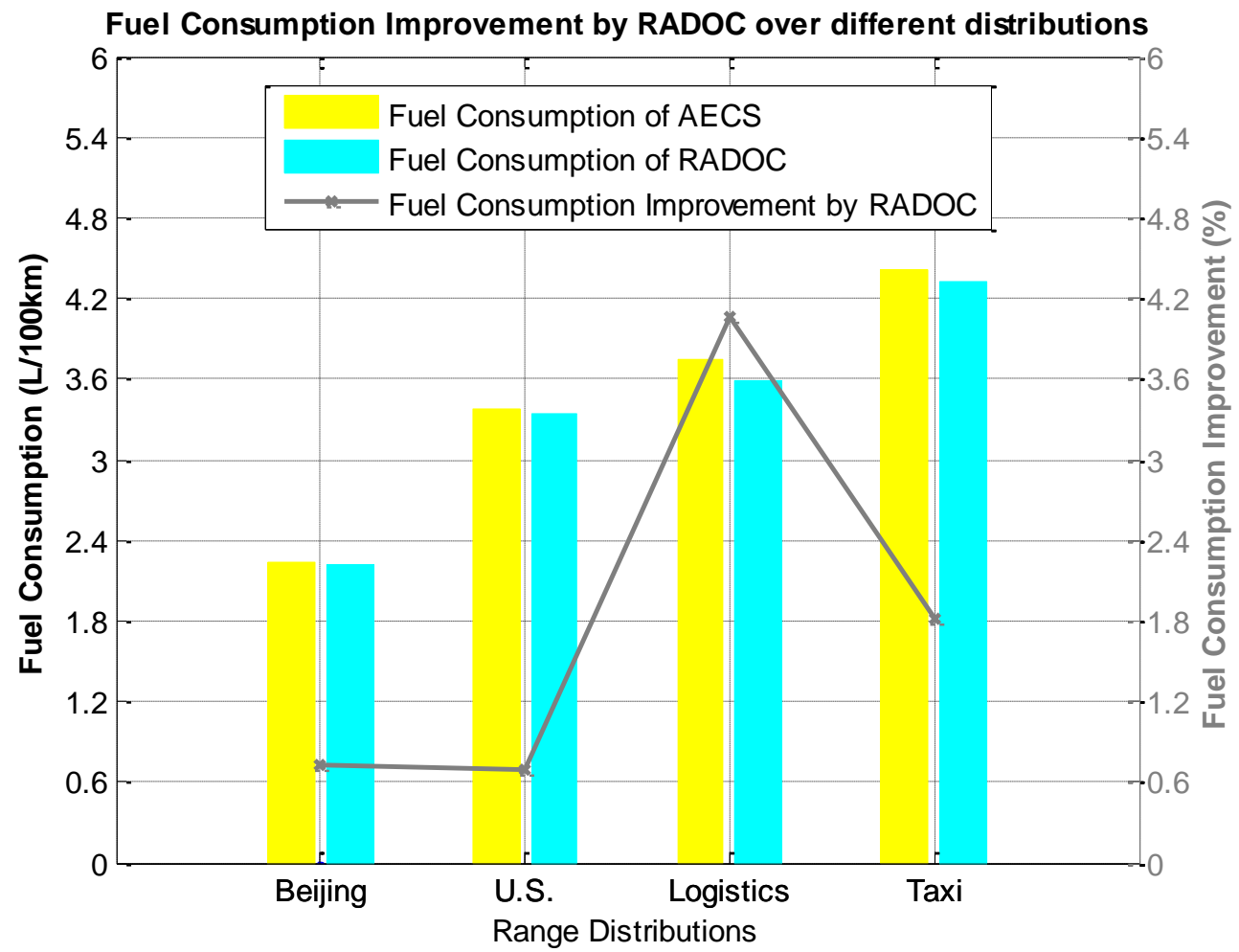

Figure 10. $\quad \mathrm{FC}_{\mathrm{UFW}}$ comparison of different range distributions 

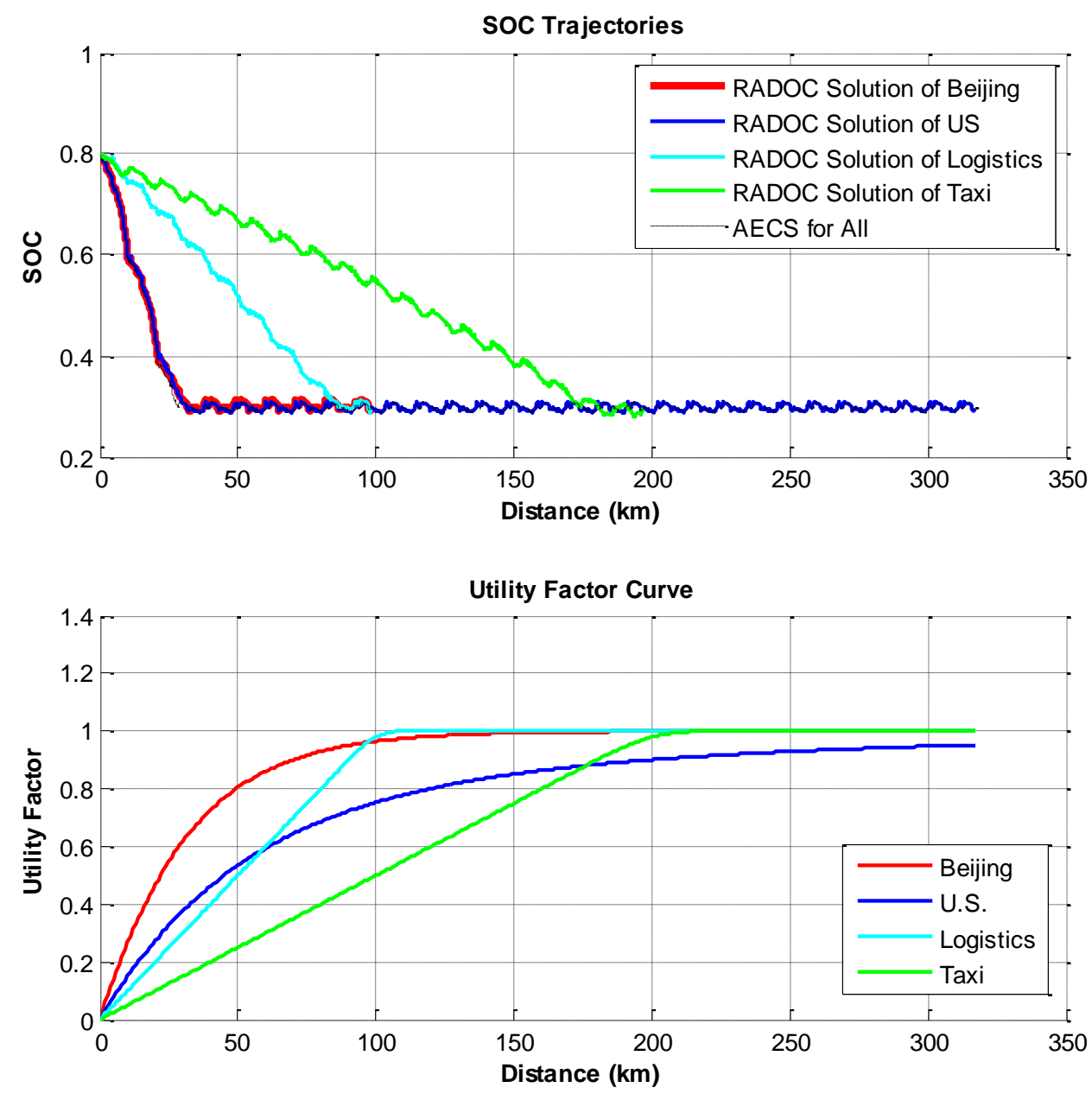

Figure 11. SOC and UF curve comparisons of different range distributions 


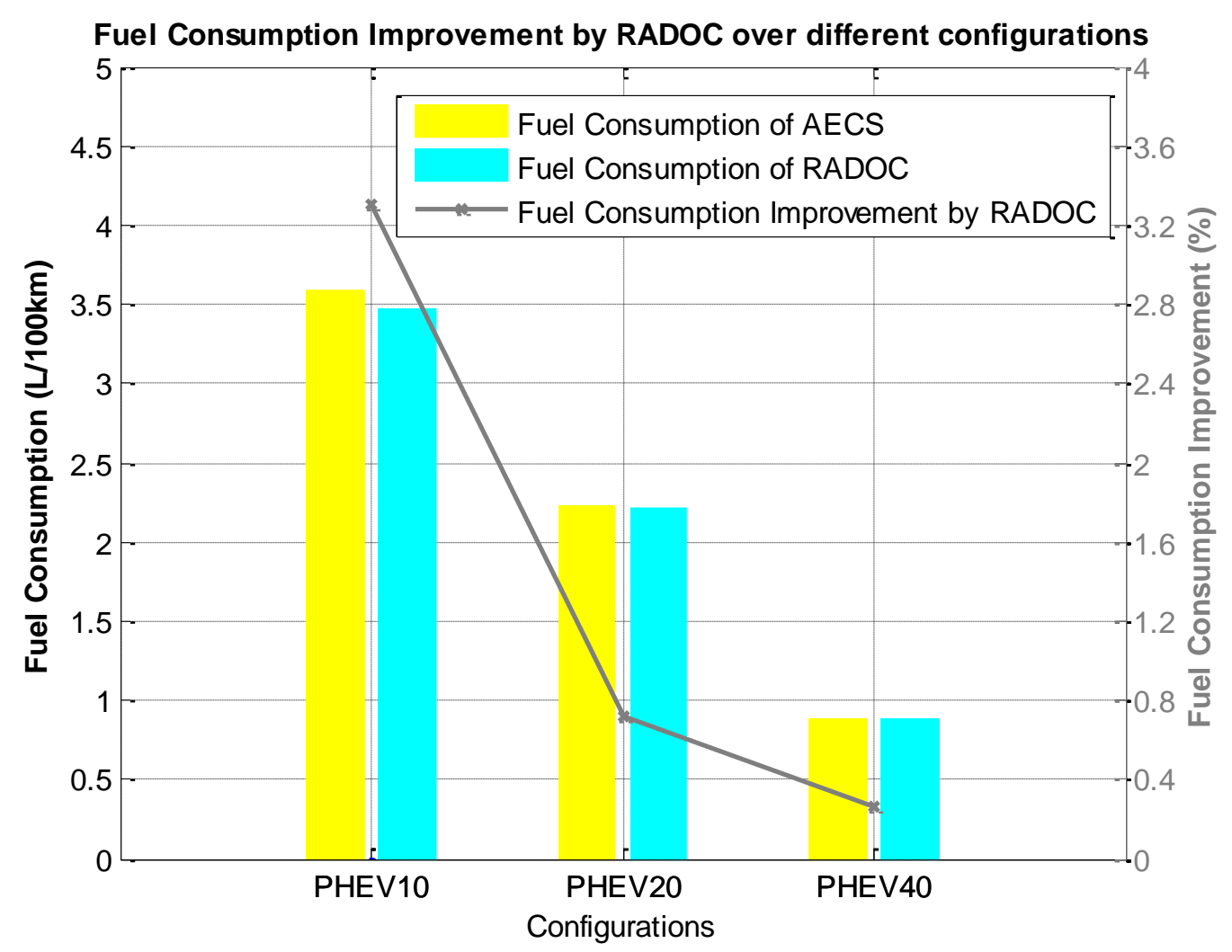

Figure 12. $\quad \mathrm{FC}_{\mathrm{UFW}}$ comparison of different configurations

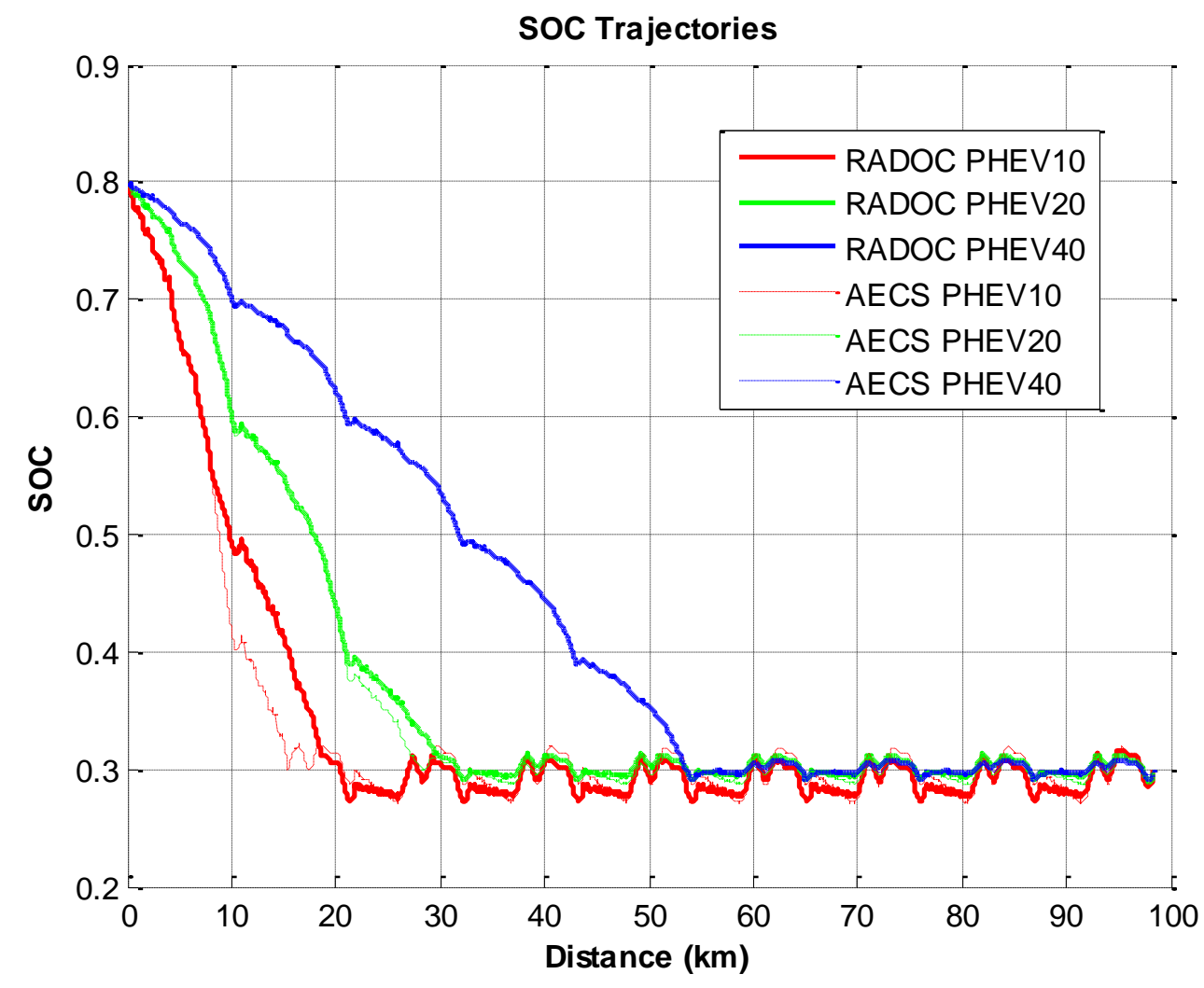

Figure 13. SOC comparison of different configurations 


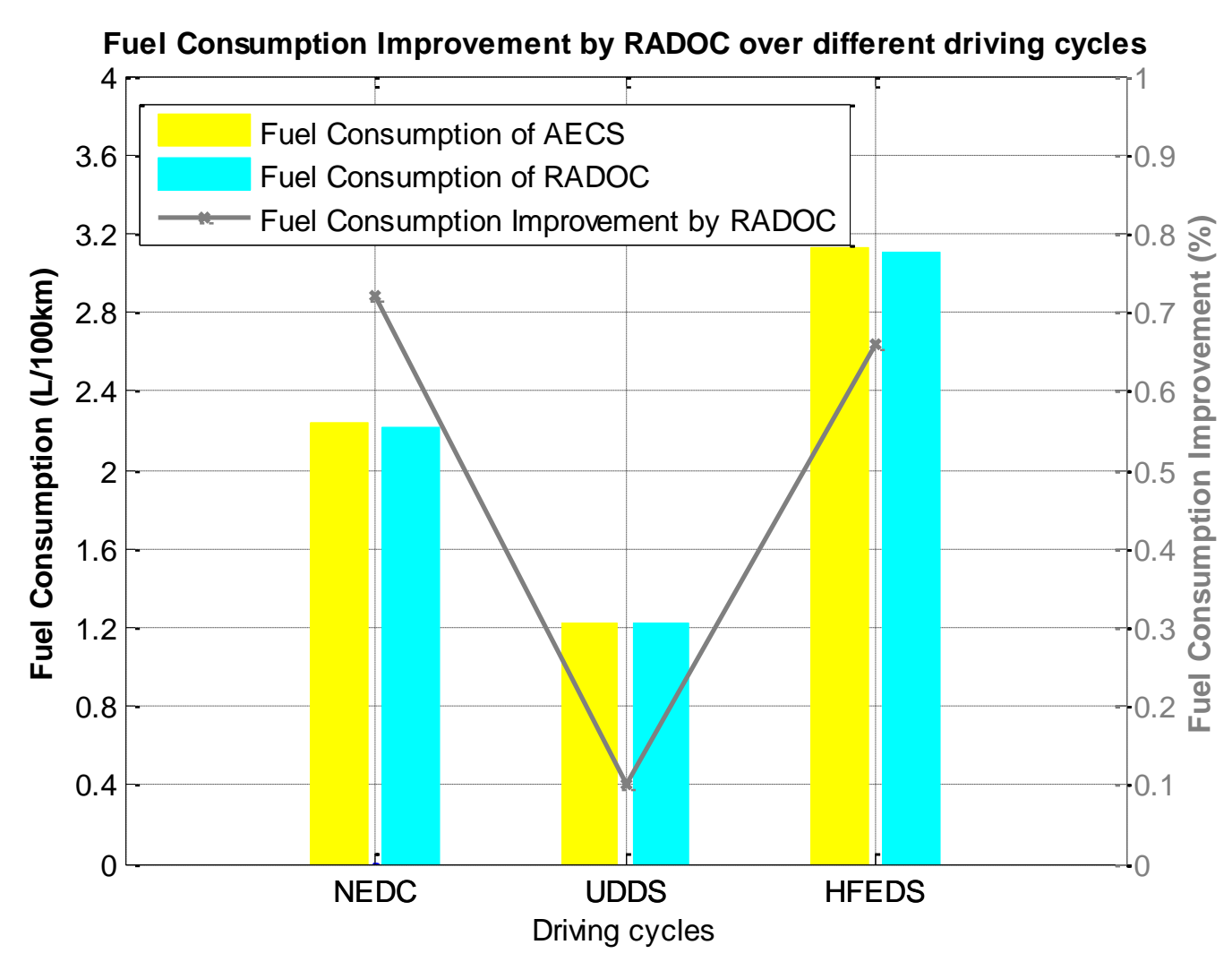

Figure 14. $\quad \mathrm{FC}_{\mathrm{UFW}}$ comparison of different driving cycles

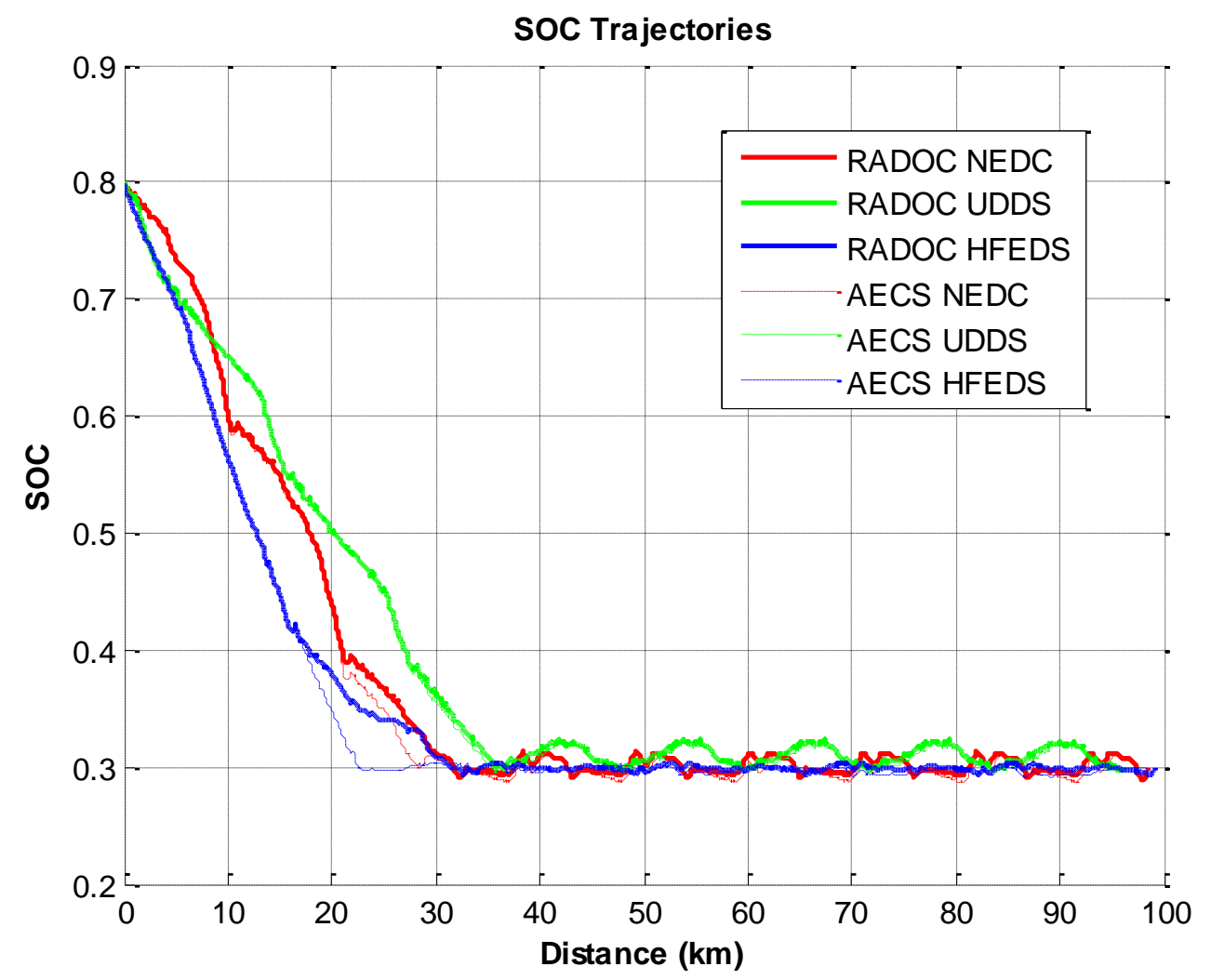

Figure 15. SOC comparison of different driving cycles 
Table 1. Results of different range distributions

\begin{tabular}{ccccc}
\hline & Beijing & US & Logistics & Taxi \\
\hline Cycles required & 9 & 29 & 9 & 18 \\
\hline AECS $(\mathbf{L} / \mathbf{1 0 0 k m})$ & 2.24 & 3.37 & 3.74 & 4.41 \\
\hline RADOC $(\mathbf{L} / \mathbf{1 0 0 k m})$ & 2.22 & 3.35 & 3.59 & 4.33 \\
\hline Improvement & $0.72 \%$ & $0.69 \%$ & $4.07 \%$ & $1.82 \%$ \\
\hline
\end{tabular}

Table 2. Results of different configurations

\begin{tabular}{cccc}
\hline & PHEV10 & PHEV20 & PHEV40 \\
\hline Cells in total & 100 & 200 & 400 \\
\hline Cells in series & 100 & 100 & 100 \\
\hline Modules in parallel & 1 & 2 & 4 \\
\hline ECMS factor $(\mathbf{k g})$ & -1.02 & -2.06 & -4.12 \\
\hline $\begin{array}{c}\text { CS Fuel Consumption } \\
\text { (L/100km) }\end{array}$ & 5.13 & 5.09 & 5.15 \\
\hline AECS (L/100km) & 3.59 & 2.24 & 0.89 \\
\hline RADOC (L/100km) & 3.47 & 2.22 & 0.88 \\
\hline Improvement & $3.30 \%$ & $0.72 \%$ & $0.26 \%$ \\
\hline
\end{tabular}

Table 3. Results of different driving cycles

\begin{tabular}{cccc}
\hline & NEDC & UDDS & HFEDS \\
\hline Cycle range $(\mathbf{k m})$ & 10.93 & 11.99 & 16.51 \\
\hline Range coverage & & 0.95 & \\
\hline Cycles required & 9 & 8 & 6 \\
\hline ECMS factor(kg) & -2.06 & -2.07 & -1.96 \\
\hline CS Fuel Consumption $(\mathbf{L} / \mathbf{1 0 0 k m})$ & 5.09 & 3.87 & 6.08 \\
\hline AECS $(\mathbf{L} / \mathbf{1 0 0 k m})$ & 2.24 & 1.22 & 3.13 \\
\hline RADOC $(\mathbf{L} / \mathbf{1 0 0 k m})$ & 2.22 & 1.22 & 3.11 \\
\hline Improvement & $0.72 \%$ & $0.10 \%$ & $0.66 \%$ \\
\hline
\end{tabular}

